\title{
Apropiación y control de recursos en la expansión urbana. La periferia metropolitana como espacio de disputa entre actores sociales
}

\section{Appropriation and control of resources in urban expansion. The metropolitan periphery as a disputed space among social actors}

\author{
Ismael Mejía Hernández* \\ Carolina Inés Pedrotti**
}

\begin{abstract}
Resumen
En este artículo se presenta a los pueblos originarios y sus lógicas de acción como parte del conjunto de actores que configuran e influyen en el proceso de urbanización en la periferia metropolitana del Valle de México. Ellos son quienes han poblado tradicionalmente estos espacios y han utilizado los recursos básicos del territorio para su asentamiento, empleo y subsistencia. Lo anterior les otorgó históricamente cierto margen de autoridad y control sobre dichos recursos, situación que ha ido cambiando e incluso perdiéndose con el tiempo, dados los procesos de poblamiento y transformación de su entorno inmediato, y la consecuente intervención de otros actores, con quienes hoy disputan estos recursos, especialmente el suelo urbanizable y el agua, elementos indispensables para la urbanización.
\end{abstract}

Palabras clave: pueblos originarios; urbanización de la periferia; conjuntos urbanos; tierra; agua.

\footnotetext{
Abstract

This article presents the pueblos originarios (indigenous people) and their logics of action as part of the set of actors that influence and shape the urbanization process

* El Colegio Mexiquense A.C. Dirección: Ex Hacienda Santa Cruz de los Patos s/n, Zinacantepec, Estado de México. Correo: omecuauhtli@hotmail.com ORCID: https://orcid. org/0000-0003-3857-6710

**El Colegio Mexiquense, A.C. Correo: cpedrotti@cmq.edu.mx ORCID: https://orcid. org/0000-0003-0379-8831
} 
in the metropolitan periphery of the Valley of Mexico. Those are the ones who have traditionally populated these spaces and have used the territory's basic resources for their settlement, employment and subsistence. The mentioned characteristics gave them historically some margin of authority and control over such resources, a situation that has been transformed and even lost over time, given the processes of settlement and transformation of their immediate environment, and the consequent intervention of other actors, with whom today they dispute their resources, especially land and water, key elements for urbanization.

Keywords: original towns, metropolitan periphery, urban ensembles, land, water.

\section{Introducción}

Desde inicios de la segunda mitad del siglo XX, el crecimiento urbano de la Ciudad de México se extendió a los municipios mexiquenses que colindan con sus delegaciones -actualmente alcaldías-, conformando con ello una periferia de considerable magnitud, que la posiciona en los primeros lugares entre las grandes regiones urbano-metropolitanas del mundo. En 1950, la Zona Metropolitana de la Ciudad de México estaba formada por 10 delegaciones y un municipio mexiquense, alcanzando en 2010 una cifra de 16 delegaciones del Distrito Federal y 60 municipios de los estados de México e Hidalgo ${ }^{1}$ (Conapo, 2012). Así, según datos censales, de una población cercana a los tres millones de habitantes en 1950, se alcanzan en 2010 los 20 millones, lo que denota una gran velocidad de crecimiento, así como el peso poblacional de los municipios metropolitanos incorporados.

En varios de estos municipios, los nuevos asentamientos de población urbana se establecieron en torno (colindando con, o incorporando) a los pueblos originarios, ${ }^{2}$ quienes históricamente habían ocupado el territorio para su asentamiento, a través de fundos legales heredados desde la época

${ }^{1}$ Aunque las cifras varían de acuerdo con los objetivos de la delimitación de la categoría metropolitana (Fernández y De la Vega, 2017, pp. 189-190).

${ }^{2}$ En la actualidad existe un debate respecto a la definición y designación de los asentamientos históricos que han sido incorporados a la ciudad; de ahí que algunos investigadores los llamen pueblos originarios (Medina, 2007), espacios ancestrales (Duhau y Giglia, 2008) e incluso pueblos urbanos (Álvarez, 2011), considerando su incorporación a la urbanización; si bien la investigación de este fenómeno es relativamente reciente, al respecto ya existe una vasta bibliografía. Para mayor detalle sobre este debate, puede revisarse Mejía, 2018.

En el presente trabajo, optamos por utilizar la categoría de pueblos originarios porque es la que asumen los habitantes de estos asentamientos; además, porque se considera que justamente es el atributo de originario el que dota al sujeto de estudio de la historicidad sobre la cual han construido sus prácticas y una narrativa como sujetos diferenciados de otros actores en el territorio de la periferia. 
colonial, ${ }^{3}$ y aprovechando los derechos adquiridos con el establecimiento de la propiedad social que les fuera dotada y/o restituida con la Reforma Agraria de inicios del siglo XX.

De origen, la tierra dotada en propiedad social tuvo como finalidad principal su explotación con fines productivos, generalmente para actividades agrícolas, ganaderas y forestales, e incluso otras como la extracción de minerales. Conforme se extendió la urbanización de la metrópoli, en un contexto de empobrecimiento del campo y de presión demográfica para la ocupación del espacio, la tierra que se encontraba en la entonces periferia fue perdiendo su valor de uso rural-agrícola y adquirió un atractivo valor de uso urbano (Salazar, 2010, 2014; Cruz, 2008); de manera complementaria, creció la demanda de agua para el consumo en actividades urbanas para satisfacer las necesidades de los nuevos asentamientos.

Esta situación vino a modificar las dinámicas que se habían construido en torno al acceso, uso y control de la tierra y el agua para los habitantes de los pueblos, quienes recurrieron a una serie de prácticas -unas legales y otras ilegales- para proteger o aprovechar sus derechos adquiridos respecto a estos recursos. Así, en el nuevo escenario territorial que se fue conformando, la aparición de otros actores interesados en éstos para fines urbanos, dio lugar a un contexto de disputa en diferentes ámbitos: político, social, jurídico y espacial.

En tal sentido, este trabajo aborda la manera en que los pueblos originarios ubicados en la periferia metropolitana se han convertido en un actor relevante en la definición de la expansión urbana, sobre todo en las últimas tres décadas, por el control histórico que han tenido sobre los recursos para la urbanización, que continúa vigente en prácticas de resistencia y, en algunos casos, de actitud-voluntad de negociación. De la misma forma, se pretende dar cuenta del impacto diferenciado sobre el control de dichos recursos, de acuerdo con el tipo de poblamiento desarrollado en su entorno (colonias populares y conjuntos urbanos habitacionales).

${ }^{3}$ Muy brevemente diremos que, como antecedente, el fundo legal implicó una primera concesión de tierras para los pueblos indígenas por parte de la Corona española. Para el caso concreto de los pueblos en estudio, la dimensión de su fundo legal ascendía a 600 varas ( 1 vara $=83 \mathrm{~cm}$ ) y sobre ellas se estableció el núcleo urbano de estos pueblos. Esto, de acuerdo con el Inventario de Bienes de Comunidad realizado por la Corona española a principios del siglo XIX, donde se ha podido identificar que los pueblos Santo Tomás Chiconautla y San Pablo Tecalco registraron la posesión de esa porción y tipo de tierras (AGN. Instituciones coloniales. Indios. Vol. 79. 15176.1. Exp. 1). Actualmente, en el área donde se demarcó este fundo legal se encuentra lo que se reconoce como el centro o casco histórico de estos pueblos, donde se hallan establecidas las oficinas administrativas y su iglesia. 
Se analizan de manera particular los casos de los pueblos Santo Tomás Chiconautla y San Pablo Tecalco, ubicados al nororiente de la metrópoli de la Ciudad de México, en los municipios de Ecatepec de Morelos y Tecámac de Felipe Villanueva, respectivamente, en el Estado de México. En términos generales, éstos comparten con otros pueblos características identitarias similares: a) son asentamientos históricos de origen indígena en su composición socioétnica; ${ }^{4}$ b) fueron dotados con tierra ejidal, o bien restituida la tierra comunal durante el periodo posrevolucionario; $c$ ) tienen comités de agua autónomos que administran los recursos acuíferos del pueblo para sus habitantes y sólo en ciertos casos abastecen a los asentamientos de su entorno; y d) se encuentran en el primero y segundo anillos de conurbación de la metrópoli de la Ciudad de México.

De manera específica, existen otras características interesantes para su selección: los municipios en los que se encuentran estos pueblos a los que concretamente haremos referencia comparten frontera entre sí, y si bien ambos han crecido con patrones de urbanización diferenciada, también se han visto impactados recientemente por el tipo de poblamiento de conjuntos habitacionales - conjuntos urbanos-, más que por colonias populares, por lo que se ha identificado en los últimos años una serie de conflictos por el control de la tierra y el agua para la urbanización de estas nuevas áreas.

En tal sentido, nos encontramos con que el espacio que ocupa la periferia metropolitana de la Ciudad de México ha ido cambiando a lo largo del tiempo, incorporando no sólo nuevos territorios sino nuevos actores, quienes utilizan instrumentos jurídicos, económicos, políticos y sociales específicos para negociar y/o disputarse el territorio; justo en ese marco está pensado este artículo.

Cabe precisar, además, que el trabajo pretende aportar a la profundización de los estudios sobre la gran diversidad de áreas que componen la periferia metropolitana, puesto que continúa siendo una perspectiva (ya menos común, pero todavía estereotipada, e incluso estigmatizante) la de pensar ésta como área homogénea, con problemáticas compartidas entre sus residentes, también homogéneos (Segura, 2011). En tal caso, reforzamos la afirmación de que la periferia es heterogénea, territorial y socialmente, y que esa heterogeneidad está presente en los distintos grupos sociales que la conforman y habitan, expresándose en sus lógicas por el control de los recursos que ésta ofrece.

\footnotetext{
${ }^{4}$ Una característica que comparten los habitantes de los pueblos originarios es que no se asumen como indígenas, sin embargo, sí su descendencia; esto los ha puesto en una situación de ambivalencia identitaria entre mestizos e indígenas, la cual utilizan de acuerdo con la situación en que se encuentren y les sea conveniente (López, 2017, pp. 277-282).
} 
El trabajo está estructurado en cuatro apartados: primero, se presenta un apartado breve sobre la relación histórica de los pueblos con la ciudad, en el marco de la expansión metropolitana de la Ciudad de México; segundo, se señala el marco de análisis que propone el trabajo para acercarse y conocer el fenómeno de la urbanización de los pueblos periféricos, considerando la identificación de los actores y sus lógicas de acción en el territorio; el tercer apartado se organiza en dos secciones: la primera describe la zona de estudio, los dos pueblos seleccionados, y los patrones de urbanización de su entorno inmediato; la segunda identifica a los actores sociales involucrados y expone sus lógicas de acción para el acceso, control y aprovechamiento de los recursos para la urbanización; el cuarto apartado presenta una breve discusión y las conclusiones del documento.

\section{De pueblos originarios a pueblos urbano-metropolitanos. Los pueblos en su relación con la ciudad}

En el momento de abordar la relación que tienen los pueblos que se encuentran en la periferia metropolitana de la Ciudad de México con la ciudad y con lo urbano, nos encontramos con una situación que no es nueva, porque si algo tiene de particular el espacio de la actual metrópoli es su ocupación previa (por varias generaciones) por núcleos de población, en su momento mayoritariamente indígenas, quienes cuando menos desde la época colonial han mantenido una relación social y funcional-territorial que se extiende hasta la actualidad.

Sin embargo, es hasta el siglo XX cuando el impacto de lo urbano sobre los recursos de los pueblos se vuelve más intensivo, sobre todo porque después de la Reforma Agraria, varios de los pueblos que se encontraban en el interior o en las inmediaciones de la capital se convirtieron en beneficiarios de tierras por medio de la restitución o dotación agraria. Si bien se esperaba que estas tierras respondieran a una vocación productiva, en la parte norte, oriente y poniente de la metrópoli fueron utilizadas en un primer momento para esos usos, y con el transcurso del siglo se convirtieron en un verdadero atractivo para usos urbanos.

En varios casos, esto sucedió mediante una urbanización irregular e ilegal, y en otros a través de la expropiación federal, figura jurídica que permitía el cambio de régimen de la propiedad social.

De tal manera, en el transcurso de la segunda mitad del siglo XX el entorno inmediato de los pueblos mexiquenses que se encontraban en el primer anillo de conurbación con la Ciudad de México amplió y profundizó 
su contigüidad física con ella, lo que implicó una presión para que la tierra que hasta ese momento era utilizada principalmente para usos agrícolas se transformara en suelo urbano (véase el Cuadro 1).

\section{Cuadro 1}

Incorporación de tierras de propiedad social al área urbana en municipios mexiquenses con presencia de pueblos

\begin{tabular}{|c|c|c|c|c|c|}
\hline Municipio & Superficie & $\begin{array}{l}\text { Cantidad } \\
\text { pueblos }\end{array}$ & $\begin{array}{l}\text { Superficie } \\
\text { tierra } \\
\text { propiedad } \\
\text { social } \\
\end{array}$ & $\begin{array}{l}\text { Porcentaje } \\
\text { tierra } \\
\text { propiedad } \\
\text { social } \\
\end{array}$ & $\begin{array}{c}\text { Año } \\
\text { incorporación } \\
\text { a zona } \\
\text { metropolitana }\end{array}$ \\
\hline $\begin{array}{l}\text { Tlalnepantla } \\
\text { de Baz }\end{array}$ & $83.48 \mathrm{~km}^{2}$ & 19 & 3322.14 ha & $39 \%$ & 1950 \\
\hline $\begin{array}{l}\text { Naucalpan } \\
\text { de Juárez }\end{array}$ & $156.60 \mathrm{~km}^{2}$ & 18 & 7250.10 ha & $46 \%$ & 1960 \\
\hline $\begin{array}{l}\text { Ecatepec } \\
\text { de Morelos }\end{array}$ & $155.49 \mathrm{~km}^{2}$ & 9 & 3699.74 ha & $23.7 \%$ & 1970 \\
\hline Huixquilucan & $143.52 \mathrm{~km}^{2}$ & 11 & 1988 ha & $13 \%$ & 1970 \\
\hline
\end{tabular}

Fuente: Elaboración propia con base en Salinas, 2016; Iracheta, 2004; Aguado, 1998; Fabila y Fabila, 1958; Gobierno Municipal de Tlalnepantla de Baz, 2016; Gobierno Municipal de Ecatepec de Morelos, 2016a; Gobierno Municipal de Naucalpan de Juárez, 2016; Gobierno Municipal de Huixquilucan de Degollado, 2016.

Aquí es importante tener presente que la tenencia de la tierra en donde se desarrolló la urbanización fue de diferente tipo (social, privada e incluso pública), aunque la de origen social representó porcentajes relevantes. Para el año 1970, de acuerdo con Schteingart, 68\% del crecimiento urbano se había dado en tierras ejidales y comunales en el Distrito Federal, y 50\% sobre el mismo tipo de tierras en los municipios que en ese momento componían la metrópoli del Valle de México (Schteingart, 1989, en Cruz, 2008, p. 48).

Esta proporción fue cambiando en las décadas siguientes, de acuerdo con el Observatorio de la Ciudad de México (OCIM): ${ }^{5}$ para la década de 1970 , el crecimiento urbano fue de $64 \%$ sobre tierra privada y $27 \%$ sobre tierra ejidal y comunal. Dicha tendencia se mantuvo para la década siguiente (Cruz, 2008, p. 50).

${ }^{5}$ Este observatorio reside en la maestría de Planeación Urbana y Políticas Públicas de la Universidad Autónoma Metropolitana, unidad Azcapotzalco. 
Para la última década del siglo XX se vislumbró un ligero aumento en la incorporación de tierra de origen social en el crecimiento urbano, al registrarse un aumento de $29.7 \%$ frente a $57.8 \%$ de tierra privada (Cruz, 2008, pp. 53-54).

Lo anterior es relevante para este trabajo puesto que, si bien las características de la tenencia de la tierra para usos urbanos ha provenido de distintos orígenes en las últimas décadas, la que ha afectado directamente a los pueblos es la relativa a la propiedad social, ya que sobre ella se desarrollaron, como hemos señalado, actividades exclusivas de la población nativa (agraria, minera, forestal), excediendo incluso el ámbito de lo productivo o de la extracción de recursos, toda vez que estos grupos (al menos las primeras generaciones) habían establecido vínculos simbólicos con el territorio, generando sentido de pertenencia y arraigo hacia él.

Con respecto a otros recursos, el agua disponible en los pueblos sí fue objeto de utilización para satisfacer las necesidades de la población capitalina sin que existiera aún una continuidad territorial con la ciudad; un ejemplo interesante en la zona nororiente fue el de 1957, cuando se decidió intercambiar entre los gobiernos del Distrito Federal y el municipio de Ecatepec, agua potable extraída de una batería de pozos dentro de ese municipio - para satisfacer la demanda de la población del norte de la capital-por agua residual para el riego de los cultivos en los ejidos de la región; esto sucedió en el núcleo agrario de Santo Tomás Chiconautla (Escolero, Kralish, Martínez y Perevochtchikova, 2016, p. 417; Mejía, 2015, p. 173).

A la luz de estas y otras evidencias, a partir de la segunda mitad del siglo XX la urbanización del contexto geográfico inmediato de los pueblos mexiquenses estrechó aún más la relación que históricamente habían tenido con la ciudad, mediante la generación de procesos de conurbación de áreas que forjaron una cuasi contigüidad física entre ámbitos de distinta naturaleza; ello incidió no sólo en las dinámicas socioculturales, económicas y políticas de la población nativa, sino que expuso a la tierra urbanizable y al agua presente en estas áreas a una mayor presión para fines urbanos.

Los mecanismos sociales, políticos y jurídicos utilizados, así como el perfil de los actores que han intervenido en el uso y control de estos recursos en el transcurso de los últimos sesenta años, presentan una complejidad que merece ser explorada. Al respecto, es conveniente considerar las reformas en materia jurídica sobre la tenencia de la tierra en la normatividad urbana, así como las facultades de la autoridad municipal y los derechos que en materia cultural, política y sobre el territorio han obtenido los pueblos en los últimos veinticinco años. 


\section{Marco de análisis. Acercamiento metodológico}

En este trabajo, la perspectiva de análisis que explica la expansión urbana sobre los pueblos de la periferia metropolitana está centrada en la identificación de los actores que intervienen en esa expansión, considerando sus lógicas de acción e intereses. En tal sentido, coincidimos con la afirmación de que "el análisis de la producción o la gestión de la ciudad requiere [en consecuencia] una primera acción de identificación de los actores que intervienen y de sus relaciones a partir de sus estrategias" (Pírez, 1995, p. 14).

Cuando hablamos de actores sociales, nos referimos justamente a:

[...] las unidades reales de acción en la sociedad: tomadores y ejecutores de decisiones que inciden en la realidad local. Son parte de la base social, son definidos por ella, pero actúan como individuos o colectivos que, además, están sometidos a otras condiciones (culturales, étnico-culturales, políticas y territoriales) [Pírez, 1995, p. 10].

Si bien se busca presentar a todos los actores intervinientes en este espacio local (esta porción de la periferia metropolitana), nos interesa particularmente hacer énfasis en los actores sociales locales, como "sujetos (individuales o colectivos) cuyo comportamiento se determina en función de una lógica local y/o su comportamiento determina los procesos locales" (Pírez, 1995, p. 10). Distinguimos entonces a los habitantes de los pueblos en sus formas de organización en torno a los recursos, como un actor local con una capacidad de determinación relevante en la producción de la urbanización periférica, pero a la vez acotada a su entorno y área de influencia. Cabe señalar, como podrá observarse más adelante, que se trata de un actor que funciona en ciertos momentos como uno -homogéneo y monolítico-en sus lógicas y decisiones, mientras que, en otras circunstancias, se desagrega en grupos o subgrupos de acuerdo con ciertas variables; por lo que se dispersa, e incluso contradice, dejando manifiesta la disputa.

Este acercamiento metodológico supone dos momentos: el primero, la identificación de los actores involucrados, una primera presentación de los mismos. El segundo implica dilucidar sus intereses, recursos y estrategias, que conforman lo que entendemos como lógicas de acción en el acceso, apropiación y control de los recursos para la urbanización. Con ello, es posible entender temas tales como la propia gestión de la expansión urbana en un espacio tan heterogéneo como la periferia metropolitana, conformada por áreas de transición (entendida como transformación, pero no necesariamente como progreso, según Salazar, 2000, p. 645), espacios de modernidad que 
conviven con espacios de tradición, donde luchan por hacerse visibles actores que, por su histórico asentamiento durante varias generaciones, han adquirido y de algún modo legitimado derechos de ocupación de ese espacio; por lo tanto, son altamente influyentes en el "acceso, control, manejo y beneficio de los recursos" que ese espacio puede ofrecer (Salazar, 2000, p. 643) .

La coexistencia de modos de vida urbanos y rurales, y la presencia de habitantes originarios y avecindados, unos y otros, no siempre es armoniosa. Así, al presentar la "trama relacional" de una parte de la ciudad (Segura, 2011), descubrimos que se logran dilucidar estrategias y acciones contradictorias, que justamente convierten el territorio en un espacio de disputa, un "campo de batalla de intereses" en donde diferentes actores toman decisiones y ejecutan acciones que les permitan asegurarse el acceso y/o control sobre ciertos recursos naturales de un determinado lugar o región (Brenner, 2010, pp. 288-289). Como podrá observarse en los apartados subsiguientes, la presentación de los actores busca además distinguir la escala de intervención de cada actor (esto es, los alcances en su ámbito de operación: local, regional, global), y también reconocer dos dimensiones de análisis en la conceptualización del término "recursos": una, los recursos de origen natural que son disputados (esto es, tierra -en tanto suelo urbanizable- y agua), y otra, los recursos económicos, sociales, políticos, físicos (Uphoff, 2005, en Brenner, 2010) con los que cuentan los actores -a los que echan mano-y que ejercen para el control del territorio.

Las técnicas de investigación y fuentes que permitieron obtener la información que requiere este marco de análisis fueron las siguientes: primero, a través de la revisión bibliográfica y hemerográfica, así como de recorridos de campo y pláticas informales con los habitantes de los pueblos Santo Tomás Chiconautla y San Pablo Tecalco, se identificaron los actores que han intervenido en los últimos veinticinco años en las actividades que representaron en su momento la vocación económica de estos territorios (como la agricultura), y que actualmente se mantienen en menor medida para la gestión y control de los recursos (tierra y agua) que se encuentran en el interior y en el entorno de los pueblos. Para el conocimiento de sus lógicas de acción, se diseñaron y aplicaron diversos instrumentos, tales como: $i$ ) entrevistas cualitativas semiestructuradas a los diversos informantes (según su perfil y responsabilidades); ii) recorridos de campo (acompañados de un registro fotográfico) para la identificación del núcleo urbano del pueblo, de las tierras ejidales y comunales, así como de aquellas ocupaciones de la tierra para fines urbanos en los últimos veinticinco años; iii) observación no participante, por medio de la asistencia a las asambleas públicas convocadas por los comités autónomos independientes de agua potable. 


\section{EI caso de estudio: patrones de urbanización y perfiles de actores en los pueblos periféricos del nororiente de la metrópoli}

\section{Patrones de urbanización}

Los pueblos que se analizan en el presente trabajo están ubicados en dos municipios mexiquenses de la zona nororiente de la capital del país: Ecatepec de Morelos, que colinda con la Ciudad de México y forma parte del primer anillo de conurbación de la metrópoli; su integración a la misma se da en la década de 1960. Tecámac, por su parte, se encuentra en el segundo anillo de conurbación y comparte frontera por el lado sur con Ecatepec; su incorporación a la metrópoli se da en la década de 1980 (véase el Mapa 1).

Hasta la década de 1950 Ecatepec, y en la de 1980 Tecámac, mantenían características rurales, con una población dedicada principalmente a actividades campesinas, establecida en núcleos de población históricos como pueblos, barrios y rancherías. A partir de la segunda mitad del siglo XX esta situación comenzó a transformarse con la combinación de una serie de políticas de Estado para la creación de corredores industriales en diversos municipios mexiquenses.

Desde ese momento y hasta la década de 1980, la economía del municipio de Ecatepec estuvo ligada directamente al sector manufacturero, aunque para inicios de la siguiente década comenzó una desocupación de la industria del municipio y un aumento del sector servicios (Bassols y Espinosa, 2011, pp. 185 y 206).

De forma paralela a la llegada de la industria a Ecatepec, el territorio municipal se fue ocupando para la instalación de viviendas, en dirección sur-norte, primeramente alrededor de los pueblos y del corredor industrial, para posteriormente ocupar lugares más alejados de estos dos puntos, en el espacio que anteriormente ocupaba el lago de Texcoco, y que, con su desecación casi total, contribuyó a la oferta de suelo urbano para cubrir las necesidades de la población que llegaba al municipio.

Allí se produjo principalmente un tipo de poblamiento por colonias populares $^{6}$ en relación con otros núcleos de población. Según el Plan de Desarrollo Municipal de Ecatepec vigente, en 2015 se registraban 8 pueblos, 6 ejidos, 12 barrios, 163 fraccionamientos y 359 colonias (Gobierno Municipal de Ecatepec de Morelos, 2016a, p. 67).

\footnotetext{
${ }^{6}$ Se utiliza la definición de colonia popular establecida por el OCIM: “AGEB con más de $50 \%$ de su superficie ocupada por asentamientos que son o alguna vez fueron irregulares en cuanto a tenencia del suelo y al apego a la normatividad urbana vigente, además de que su urbanización y la construcción de viviendas se realizan de manera progresiva" (Connolly, 2014, p. 392).
} 


\section{Mapa 1}

\section{Ubicación de los pueblos Santo Tomás Chiconautla y San Pablo Tecalco}

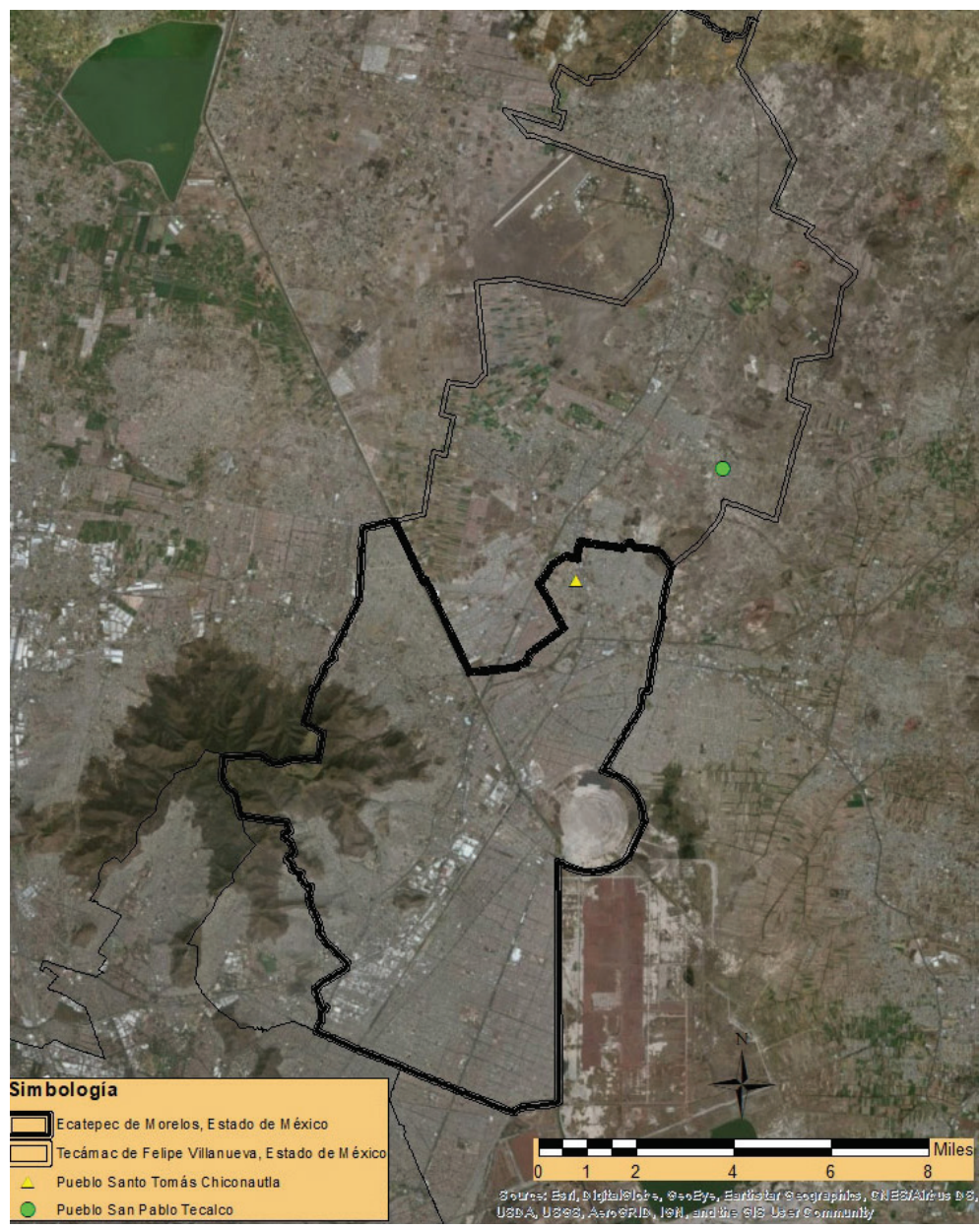

Fuente: Elaboración de Ismael Mejía Hernández, con base en Arcgis 2018. 
Justamente es en la parte norte del municipio -la de más reciente urbanización-, sobre la tierra de los núcleos agrarios de los pueblos Santo Tomás y Santa María Chiconautla, ${ }^{7}$ donde comenzaron a instalarse conjuntos urbanos habitacionales $^{8}$ al final de la década de 1990 (véase el Cuadro 2). ${ }^{9}$

\section{Cuadro 2}

Cantidad de viviendas y número de habitantes en Ecatepec, 1970-2015

\begin{tabular}{lccrrrr}
\hline Año & $\mathbf{1 9 7 0}$ & $\mathbf{1 9 8 0}$ & $\mathbf{1 9 9 0}$ & \multicolumn{1}{c}{$\mathbf{2 0 0 0}$} & \multicolumn{1}{c}{$\mathbf{2 0 1 0}$} & \multicolumn{1}{c}{$\mathbf{2 0 1 5}$} \\
\hline Viviendas & 34502 & 130470 & 238413 & 364657 & 419087 & 436963 \\
Población & 216408 & 784507 & 1218135 & 1622697 & 1656107 & 1677678 \\
\hline
\end{tabular}

Fuente: Elaboración propia con información de los Censos de Población y Vivienda, IX, X, XI, XII, XIII y la Encuesta Intercensal 2015 (INEGI, 1970, 1980, 1990, 2000, 2010, 2015).

El patrón de urbanización del municipio de Tecámac ha sido diferente al de Ecatepec; si bien comparten frontera entre sí, su ubicación geográfica un tanto más alejada del centro metropolitano no resultó ser tan atractiva en un primer momento para la urbanización de su territorio.

Hasta la década de 1960, Tecámac estaba ocupada principalmente por sus pueblos (Correa, 2010, p. 74; Granillo, 2006, p. 43), cuya población se dedicaba económicamente a actividades campesinas.

En 1970 comenzaron a instalarse colonias populares en el territorio municipal, principalmente alrededor de los pueblos -según datos de Granillo (2006, p. 48), 34 de 51 colonias que se formaron en esa década y

${ }^{7}$ Si bien a principios de la década de 1980 varias hectáreas de estos dos núcleos agrarios fueron utilizadas para la instalación de colonias populares, la mayor parte de la tierra de Santo Tomás Chiconautla, y en menor medida la de Santa María, fue transferida a la empresa Sadasi, para la instalación del conjunto urbano Los Héroes.

${ }^{8}$ Los conjuntos urbanos representan un modelo de construcción de vivienda en serie que empezó a proliferar en la periferia metropolitana para sectores económicos medios y medios bajos a partir de la década de 1990, producidos por el sector privado inmobiliario y en general financiados por los Onavis (Organismos Nacionales de Vivienda). Para el caso del Estado de México, la normativa urbana los describe de la siguiente manera: "Se denomina conjunto urbano a la modalidad que se adopta en la ejecución del desarrollo urbano que tiene por objeto estructurar o reordenar, como una unidad espacial integral, el trazo de la infraestructura vial, la división del suelo, las normas de usos, aprovechamientos y destinos del suelo, las obras de infraestructura, urbanización y equipamiento urbano, la ubicación de edificios y la imagen urbana de un predio ubicado en áreas urbanas o urbanizables" (Código Administrativo del Estado de México).

${ }^{9}$ Conviene señalar que la denominación de la variable utilizada en los diferentes ejercicios censales para la vivienda cambia: en 1970 la variable es total de viviendas, en 1980 es viviendas colectivas, en 1990 y 2000 es total de viviendas habitadas, y en 2010 y 2015 es total de viviendas particulares habitadas. 
hasta mediados de 1990 se ubicaron alrededor de los pueblos-. Sin embargo, esto se dio a un ritmo mucho menor que en Ecatepec, en algunos casos incluso como parte del crecimiento natural de la población existente en los pueblos.

Al final de la década de 1990 e inicios del siglo XXI, se empezó a desarrollar un tipo de poblamiento mediante la instalación de conjuntos urbanos en diversas partes del territorio municipal.

La cuantiosa producción habitacional generada con este tipo de desarrollos inmobiliarios incidió para que el municipio formara parte del proyecto Ciudades Bicentenario, que planteaba de origen "[...] crear proyectos inmobiliarios de más de 155 mil viviendas en la periferia de la Ciudad de México, aprovechando los recursos naturales, la infraestructura y los servicios ya existentes en la Zona Metropolitana y en la Ciudad de México" (Espinosa, 2014).

La instalación de conjuntos urbanos y el consiguiente desarrollo de infraestructura urbana propició una nueva configuración en la ocupación del territorio, si bien en dirección de sur a norte, pero no necesariamente promoviendo la continuidad territorial, sino de tipo insular, ${ }^{10}$ de manera discontinua, dispersa, en diferentes áreas del municipio.

De 2000 a 2015 la población municipal casi se triplicó, y el número de viviendas aumentó en más de 300\% (véase el Cuadro 3).

\section{Cuadro 3}

Cantidad de viviendas y número de habitantes en Tecámac, 1970-2015

\begin{tabular}{lccrrrc}
\hline Año & $\mathbf{1 9 7 0}$ & $\mathbf{1 9 8 0}$ & $\mathbf{1 9 9 0}$ & $\mathbf{2 0 0 0}$ & $\mathbf{2 0 1 0}$ & \multicolumn{1}{c}{$\mathbf{2 0 1 5}$} \\
\hline Viviendas & 3461 & 14964 & 20074 & 36443 & 97147 & 122551 \\
Población & 20882 & 84129 & 123218 & 172813 & 364579 & 446008 \\
\hline
\end{tabular}

Fuente: Elaboración propia con información de los Censos de Población y Vivienda, IX, X, XI, XII, XIII y la Encuesta Intercensal 2015 (INEGI, 1970, 1980, 1990, 2000, 2010, 2015).

De acuerdo con el Plan de Desarrollo Municipal de Tecámac 20162018, en el año 2015 los núcleos de población que se encontraban en el municipio eran 12 pueblos, 56 colonias, 2 fraccionamientos, 24 conjuntos urbanos, 4 barrios y 4 ranchos (Gobierno Municipal de Tecámac de Felipe Villanueva, 2016).

${ }^{10}$ Como lo han señalado Duhau y Giglia (2008, pp. 135-153), el modelo de urbanización insular tiene como características fundamentales ser un espacio residencial cerrado, conectado por vialidades que permitan la movilidad y estar rodeado por centros comerciales que ofrezcan los servicios necesarios a sus habitantes. 
Como se observa entonces, previo a la urbanización masiva de estos dos municipios ya se encontraban en su territorio pueblos originarios, mismos que han mantenido una continuidad territorial y de población, cuando menos desde el periodo colonial. Santo Tomás y San Pablo conservan un patrón de asentamiento alrededor de un centro histórico en donde se encuentra una iglesia que data del periodo colonial, así como diferentes oficinas administrativas y de servicios, como la oficina del comité de agua en San Pablo o la casa de cultura en Santo Tomás (véase las Fotografías 1 y 2).

\section{Fotografía 1}

Explanada de San Pablo Tecalco

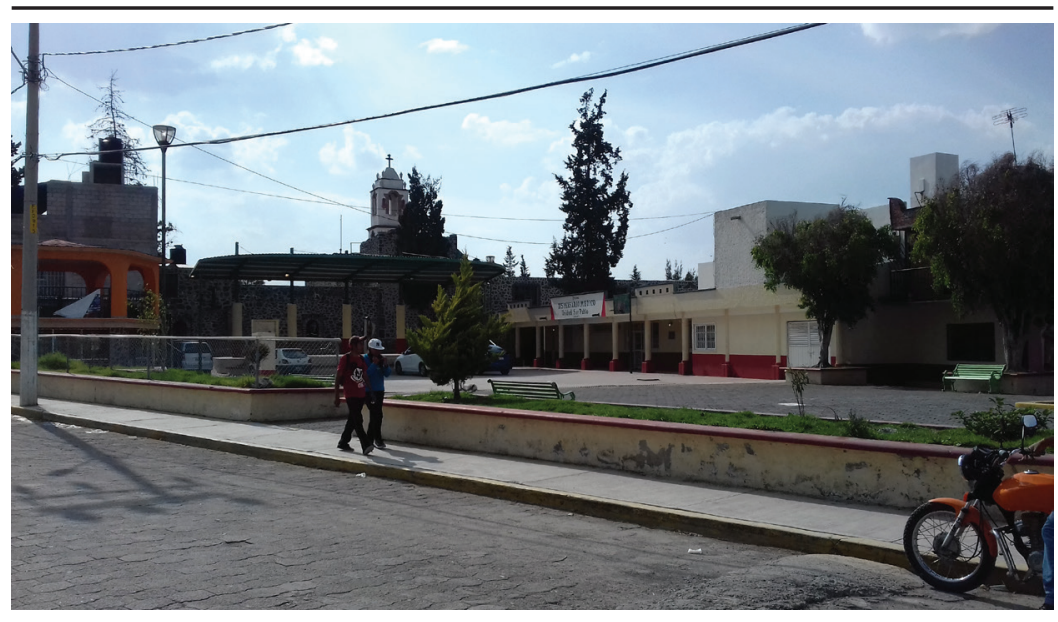

Fuente: Fotografía de Ismael Mejía, 2018.

Se puede identificar un sistema de parentesco de familias autodenominadas originarias, así como una serie de prácticas socioculturales que las distinguen ante otros, para lo cual proclaman un sentido de pertenencia territorial frente a otros núcleos de población.

Los habitantes de estos pueblos mantienen formas de organización comunitaria alrededor de sus prácticas socioculturales, identificadas principalmente con las mayordomías conformadas para las fiestas patronales, con el mantenimiento y control del cementerio, así como con la distribución del agua potable entre los habitantes del pueblo y de otras colonias contiguas de reciente creación. 


\section{Fotografía 2}

Explanada de Santo Tomás Chiconautla

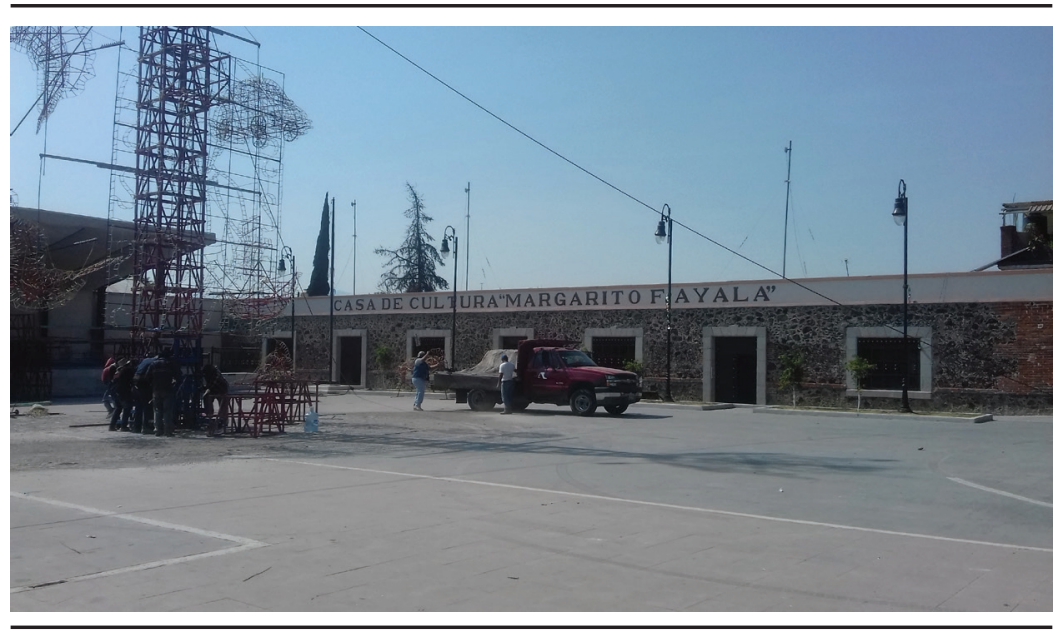

Fuente: Fotografía de Ismael Mejía, 2017.

Mención aparte es la que tiene que ver con las tierras cuyo origen es de propiedad social, ya que en los dos pueblos se conformaron núcleos agrarios a partir de la Reforma Agraria de 1915 (véase el Cuadro 4), que han presentado comportamientos diferenciados después de la reforma constitucional al artículo 27 de 1992, lo que desencadenó la apertura de un mercado de tierras periurbanas para la instalación de conjuntos habitacionales en dicha tierra de origen social.

Como hemos podido observar, antes de dicha disposición legislativa, el patrón de urbanización principal que se desarrolló alrededor de los pueblos fue del tipo de poblamiento popular, y después de ella, a través de la instalación de conjuntos urbanos. En el caso de Santo Tomás, la mayor parte de su tierra ejidal ha sido ocupada por el conjunto urbano Los Héroes. Por su parte, en San Pablo se ha desarrollado Los Héroes San Pablo, en 107 hectáreas de tierra cuyo origen es de propiedad social.

\section{Actores en torno a los recursos tierra y agua en la expansión de la metrópoli}

En este apartado nos referiremos a los actores que han intervenido directa e indirectamente en la conversión de tierra de origen social en suelo urba- 
no en los últimos veinticinco años en los alrededores de los pueblos Santo Tomás Chiconautla y San Pablo Tecalco, así como en el acceso, control y administración del agua potable.

\section{Cuadro 4}

Características de los núcleos agrarios Santo Tomás Chiconautla y San Pablo Tecalco

\begin{tabular}{|c|c|c|c|c|c|c|}
\hline $\begin{array}{l}\text { Núcleo } \\
\text { agrario }\end{array}$ & $\begin{array}{c}\text { Año } \\
\text { dotación }\end{array}$ & $\begin{array}{c}\text { Posesiones } \\
\text { anteriores } \\
\text { a dotación }\end{array}$ & $\begin{array}{c}\text { Tierras en } \\
\text { dotación } \\
\text { ejidal }\end{array}$ & $\begin{array}{c}\text { Propiedades } \\
\text { afectadas } \\
\text { por dotación }\end{array}$ & $\begin{array}{c}\text { Características } \\
\text { de terrenos }\end{array}$ & $\begin{array}{l}\text { Tierras que } \\
\text { adoptaron } \\
\text { dominio } \\
\text { pleno a } 2018 \\
\end{array}$ \\
\hline $\begin{array}{l}\text { Santo } \\
\text { Tomás } \\
\text { Chiconautla }\end{array}$ & 1929 & 406.4 ha & 1431 ha & $\begin{array}{l}\text { Hacienda } \\
\text { Ojo de Agua } \\
\text { y Venta de } \\
\text { Carpio }\end{array}$ & $\begin{array}{l}\text { De temporal, } \\
\text { de pastal } \\
\text { cerril y de } \\
\text { ciénaga }\end{array}$ & $936.23 \mathrm{ha}$ \\
\hline $\begin{array}{l}\text { San Pablo } \\
\text { Tecalco }\end{array}$ & 1925 & 589 ha & 935 ha & $\begin{array}{l}\text { Haciendas } \\
\text { Ojo de Agua, } \\
\text { San José de } \\
\text { Acolman y } \\
\text { San Miguel } \\
\text { Tenopala }\end{array}$ & $\begin{array}{l}\text { De temporal } \\
\text { y de pastal } \\
\text { cerril }\end{array}$ & 107.24 ha \\
\hline
\end{tabular}

Fuente: Elaboración propia con base en Fabila y Fabila, 1958a, 1958b; López, 1997; plano de dotación ejidal de Santo Tomás Chiconautla 598; Granillo, 1998; padrón e historial de núcleos agrarios en http://www.ran.gob.mx

Previo a esto, es fundamental considerar que en el transcurso de diez años (1992 a 2001), se sucedieron una serie de reformas legales y normativas tanto en el ámbito federal como en el estatal, que contribuyeron a afirmar o bien a modificar algunas "reglas del juego" de los actores involucrados en el proceso de expansión metropolitana de la Ciudad de México. Aquí haremos referencia específica a tres instrumentos.

El primero se dio en 1992, cuando se reformó el artículo 27 constitucional, que permitió la enajenación de la tierra de propiedad social en propiedad privada susceptible de ser incorporada al desarrollo urbano, lo que convirtió a la tierra de los núcleos agrarios de estos pueblos en un recurso sumamente atractivo para el mercado inmobiliario formal. ${ }^{11}$

${ }^{11}$ Cabe recordar que antes de dicha reforma, este tipo de tierra también fue atractiva para usos urbanos habitacionales, pero dentro del mercado informal-ilegal, por lo que los actores interesados fueron, en su mayoría, población de bajo ingreso que autoprodujo en condiciones de ilegalidad. 
Otro elemento en la legislación fue implementado por el gobierno mexiquense, quien, al inicio de 2000, como uno de los ejes rectores que sustentaron la acción de gobierno, inició un proceso de modernización integral de la administración pública, que planteaba una revisión completa de la legislación administrativa vigente en la entidad para lograr su codificación, simplificación y modernización (Gómez, 2006, en Pedrotti, 2016).

Dentro del universo de ordenamientos codificados estuvo la Ley Estatal de Asentamientos Humanos de 1993, la cual fue sustituida -así como otros instrumentos de normatividad sobre el desarrollo urbano- por el Libro Quinto del Código Administrativo, que lleva por título Del ordenamiento territorial de los asentamientos humanos y del desarrollo urbano de los centros de población. Éste incluye el sistema de planeación estatal, el contenido mínimo de los planes de desarrollo urbano, y todo lo referente a las autorizaciones urbanas de división del suelo: condominios, conjuntos urbanos, subdivisiones, fusiones, relotificaciones (Pedrotti, 2016, p. 96; Rodríguez, 2015). Es este libro, junto con su reglamento, el que refiere explícitamente el proceso de autorización, seguimiento, control y municipalización de los conjuntos urbanos habitacionales producidos por el sector inmobiliario, regulando -y con ello, legitimando- la acción de este sector en materia de vivienda.

Un tercer elemento a señalar en este trabajo corresponde a la inclusión de los derechos indígenas y culturales en la Constitución nacional (lo que inició en 1992 y continuó hasta 2001), en donde se reconoce un conjunto de derechos para los pueblos indígenas del país, particularmente en cuanto al acceso y al control de los recursos naturales. En específico, en el artículo 2 constitucional se reconoce el carácter pluricultural de la nación, sustentada en sus pueblos indígenas; se garantiza el "conservar el hábitat y preservar la integridad de sus tierras en los términos establecidos en esta Constitución", así como promover el "[...] uso y disfrute preferente de los recursos naturales de los lugares que habitan y ocupan las comunidades". ${ }^{12}$

Esta inclusión contribuyó a dar sustento jurídico y con ello a empoderar a los habitantes de estos pueblos en términos de su relación con los recursos.

Dicho esto, nos referiremos en primer lugar a los actores que se han visto involucrados en torno a la tierra, y luego a aquellos implicados con el agua de los pueblos en cuestión.

${ }^{12}$ Cabe destacar que, si bien este artículo no menciona específicamente los derechos indígenas sobre el territorio, algunos tratados internacionales que ha suscrito el Estado mexicano sí lo hacen, como el Convenio 169 de la Organización Internacional del Trabajo, lo que obliga a su cumplimiento. 
En cuanto a la tierra, mencionaremos en principio a los núcleos agrarios: éstos están integrados por un número determinado de personas que fueron acreedoras a la dotación de tierras que otorgó la Reforma Agraria en los años que estuvo vigente (1915 a 1991, según Aguado, 1998). El núcleo agrario de Santo Tomás Chiconautla está integrado por 356 personas, ${ }^{13} \mathrm{y}$ el de San Pablo Tecalco por 325 personas, ${ }^{14}$ en ambos casos denominadas ejidatarios.

Ambos núcleos agrarios están regulados por la Ley agraria, y su organización social se conforma por una mesa directiva compuesta por el comisario ejidal, el secretario y el tesorero, y un comité de vigilancia; todos son elegidos entre los miembros del núcleo agrario mediante votación cada tres años $;{ }^{15} \sin$ embargo, la autoridad máxima del núcleo agrario es la asamblea.

La cantidad total de tierras que recibió Santo Tomás durante la dotación fue de 1431 hectáreas, ${ }^{16}$ mientras que San Pablo accedió a 935 hectáreas.

Esta tierra fue parcelada de forma heterogénea entre los miembros de los núcleos agrarios: mientras que en Santo Tomás se repartieron a unos ejidatarios parcelas de 2 ha y a otros de 6.5 ha, en San Pablo la dotación inicial fue de 2 ha, y después se le agregó media hectárea por ejidatario.

Con el paso del tiempo, algunas tierras fueron pasando a manos de quienes hoy forman parte del ejido a través de sucesión hereditaria, aunque subsisten algunos casos de ejidatarios que la adquirieron en la dotación, lo que ha generado diferencias en las edades y perfiles sociales de los ejidatarios.

En el caso de Santo Tomás, Cruz (2002, p. 70) registra que, hasta mediados de la década de 1990, las tierras del núcleo agrario seguían siendo productivas al mantener un sistema de riego que garantizaba la cosecha.

Sin embargo, a finales de dicha década comenzó la enajenación de los terrenos del núcleo agrario a favor de la desarrolladora inmobiliaria Sadasi para la construcción de varias secciones del conjunto urbano Los Héroes, reduciéndose el núcleo en el año 2018 a una cantidad de tierra de poco menos de 170 hectáreas (12\% de su magnitud inicial).

En el caso de San Pablo, de acuerdo con las entrevistas realizadas a ejidatarios, la productividad de la tierra nunca ha sido buena, sobre todo

${ }^{13}$ Según el Registro Agrario Nacional, núcleo agrario Santo Tomás Chiconautla.

${ }^{14}$ Según el Registro Agrario Nacional, núcleo agrario San Pablo Tecalco.

${ }^{15}$ En el caso del núcleo agrario de San Pablo Tecalco, sólo tienen derecho a votar y ser votados quienes tienen en orden sus títulos agrarios.

${ }^{16}$ Los municipios Ecatepec de Morelos y Tecámac de Felipe Villanueva mantuvieron un litigio durante varios años por la ubicación del núcleo agrario de Santo Tomás Chiconautla; al final el juicio se resolvió a favor de Tecámac, de ahí que mientras el pueblo de Santo Tomás se encuentra en Ecatepec, las tierras ejidales de su núcleo agrario quedaron del lado de Tecámac. 
porque se trata de un suelo muy pedregoso y el núcleo agrario no cuenta con un sistema de riego. No obstante, algunos ejidatarios siembran maíz y frijol, principalmente. Lo que sí han podido aprovechar es la explotación de una mina de tezontle en el cerro de Chiconautla, que forma parte del núcleo agrario.

En la actualidad, de acuerdo con los documentos revisados en el Registro Agrario Nacional (RAN), sólo se ha obtenido el dominio pleno en 107 hectáreas $(11.5 \%$ del total), las cuales, según se ha identificado, han sido adquiridas por la desarrolladora Sadasi para la construcción del conjunto urbano Los Héroes San Pablo.

Como podemos observar, la conjunción de la reforma al artículo $27 \mathrm{y}$ la generación de un modelo de vivienda a partir de conjuntos urbanos, ha impactado la relación que tenían los integrantes de los núcleos agrarios con la tierra, sobre todo al agregar y/o transformar su valor de uso por un valor de cambio, al convertirla en un recurso atractivo para su urbanización. Sin embargo, cabe destacar que el aprovechamiento en la mercantilización del recurso no ha sido homogéneo para todos los integrantes de los núcleos agrarios, sobre todo por los recursos económicos, educativos y políticos que posee cada uno de ellos. Evidencia de esto es que el poder de las autoridades del núcleo agrario para negociar en un primer momento con las empresas desarrolladoras y su nivel de influencia con los demás ejidatarios, les generó a dichas autoridades mayores beneficios.

Otro actor identificado es el pueblo como tal, ${ }^{17}$ que, si bien no constituye necesariamente una unidad homogénea en términos sociales, ha ido apareciendo en el discurso de sus habitantes de forma progresiva, a partir de la exigencia del cumplimiento de los derechos constitucionales que como pueblos originarios argumentan tener. ${ }^{18}$

En Santo Tomás no se ha identificado tan enérgicamente una reivindicación como pueblo que haya tenido repercusiones directas con la tierra. En cambio, en el caso de San Pablo sí existen evidencias concretas del reclamo de algunos de sus habitantes, en su calidad de integrantes del pueblo originario, frente a las autoridades gubernamentales y a la empresa inmobiliaria Sadasi, que los ha llevado a interponer recursos legales y movilizaciones

${ }^{17} \mathrm{Y}$ del cual los integrantes del núcleo agrario son sólo una parte.

${ }^{18}$ Como es posible observar en este trabajo, se ha ido logrando dilucidar que, si bien se reconoce el carácter heterogéneo de los habitantes de los pueblos, existen circunstancias y escenarios donde éstos actúan de forma compacta como un actor "pueblo", sobre todo en situaciones de conflicto concretas, como el que se presenta cada vez que los ayuntamientos exigen tomar el control del sistema de agua potable que los abastece; o también, en situaciones festivas, como la organización y ejecución de las fiestas patronales. 
sociales en defensa de lo que consideran ha vulnerado sus derechos socioculturales al territorio, así como a la consulta.

También se han generado conflictos dentro del pueblo a partir de la venta de tierra ejidal, lo que ha afectado sus dinámicas socioculturales, visibilizando la diferencia entre dos actores: los ejidatarios, quienes en efecto tienen derecho sobre la tierra, y los habitantes nativos del pueblo, quienes, si bien no todos tienen derecho a la tierra ejidal, sí tienen derecho al territorio en sentido amplio y simbólico, de acuerdo con el artículo 2 constitucional y los tratados internacionales, como el Convenio 169 de la Organización Internacional del Trabajo (OIT).

Es importante destacar esto último, sobre todo porque en algunos casos se ha confundido al pueblo y al núcleo agrario como un sólo actor, incluso porque en su mayoría los núcleos agrarios tienen el mismo nombre que el pueblo (López, 2017). Sin embargo, estos nuevos escenarios que se desarrollan alrededor de la mercantilización legal de las tierras originalmente ejidales para la ocupación urbana, han permitido visibilizar la diferencia entre estos dos actores.

Por otra parte, si bien se ha construido un andamiaje jurídico en torno a los pueblos indígenas, las características de los pueblos originarios que han sido absorbidos por la mancha urbana los ha posicionado en una situación sociojurídica compleja, sobre todo por su condición de mestizos, para el reconocimiento de dichos derechos. Aun así, la visibilización a través de la movilización social y política, además del reconocimiento de la legislación local de la Ciudad de México a los pueblos originarios que se encuentran en su territorio, se ha convertido en un referente para los habitantes de San Pablo (que se encuentran en otra delimitación político-administrativa, la del Estado de México) en su exigencia de reconocimiento como tales. ${ }^{19}$

Un tercer actor es el sector inmobiliario privado, y en el caso que nos ocupa, a través de la desarrolladora inmobiliaria Sadasi, quien ha intervenido en diferentes momentos en la compra de tierra social de los núcleos agrarios para la producción de conjuntos urbanos habitacionales.

En sentido similar, los desarrolladores inmobiliarios han sido beneficiados en términos formales por una legislación específica sobre la apertura de áreas otrora rústicas para su conversión e incorporación al desarrollo urbano a través de lo establecido en el Libro Quinto del Código Administrativo (Pedrotti, 2016).

${ }^{19}$ Ya existen sentencias judiciales en donde algunos pueblos de la Ciudad de México han recibido el reconocimiento como tal, a pesar de la condición mestiza de sus habitantes, por ejemplo, el caso de los pueblos de Xochimilco (Salgado, 2017). 
En el caso de Tecámac esto también ha sido impulsado por el gobierno municipal, en donde la participación del cuatro veces presidente municipal, Aarón Urbina, ha sido relevante en la construcción de conjuntos urbanos en el territorio municipal (Ibarra, 2017, p. 94; Correa, 2010).

Esta situación ha permitido a la desarrolladora Sadasi negociar con los integrantes de los núcleos agrarios la compraventa de sus tierras, en diferentes etapas y con diversas estrategias, las cuales han tenido como premisa principal garantizar los intereses de la desarrolladora, sin exponer la viabilidad jurídica y económica de los proyectos.

La emergencia de este actor en la negociación y disputa por la tierra ha sido por demás relevante, sobre todo por la capacidad económica y política que tiene, y que se ha visto reflejada en distintos momentos y dimensiones, desde su participación en la redacción del propio Libro Quinto del Código Administrativo del Estado de México (CAEM) (Pedrotti, 2016, p. 97), hasta en el convencimiento de vender, por lo atractivo que fue para varios ejidatarios la oferta económica que se les hizo para la compra de sus terrenos.

El Cuadro 5 se ha construido con el objeto de exponer esquemáticamente los intereses, recursos y estrategias de cada actor, que en su conjunto conforman lo que en este artículo hemos llamado lógicas de acción. Al respecto, se descubrió que, por una parte, el conocimiento de los recursos y estrategias de los distintos actores ha permitido dilucidar sus intereses; por otra, éstos se rescatan de sus propios discursos. De la misma forma, se ha podido advertir un comportamiento diferenciado en el interior de cada actor colectivo, derivado de la heterogeneidad de los recursos que poseen, lo que a su vez implica la implementación de estrategias diversas (véase el Cuadro 5).

\section{Actores en torno al agua potable}

Uno de los recursos indispensables para la urbanización planeada del territorio es la suficiencia de agua potable. La reciente normatividad mexiquense al respecto indica que la autorización de conjuntos urbanos habitacionales, en su dimensión y densidad, estará sujeta a la disponibilidad de agua potable y de energía eléctrica (Reglamento del Libro Quinto del CAEM, primer párrafo del artículo 42).

El ámbito municipal de gobierno es, de acuerdo con el artículo 115 constitucional, la autoridad encargada de otorgar el servicio de "agua potable, drenaje, alcantarillado, tratamiento y disposición de sus aguas residuales" a sus habitantes. 


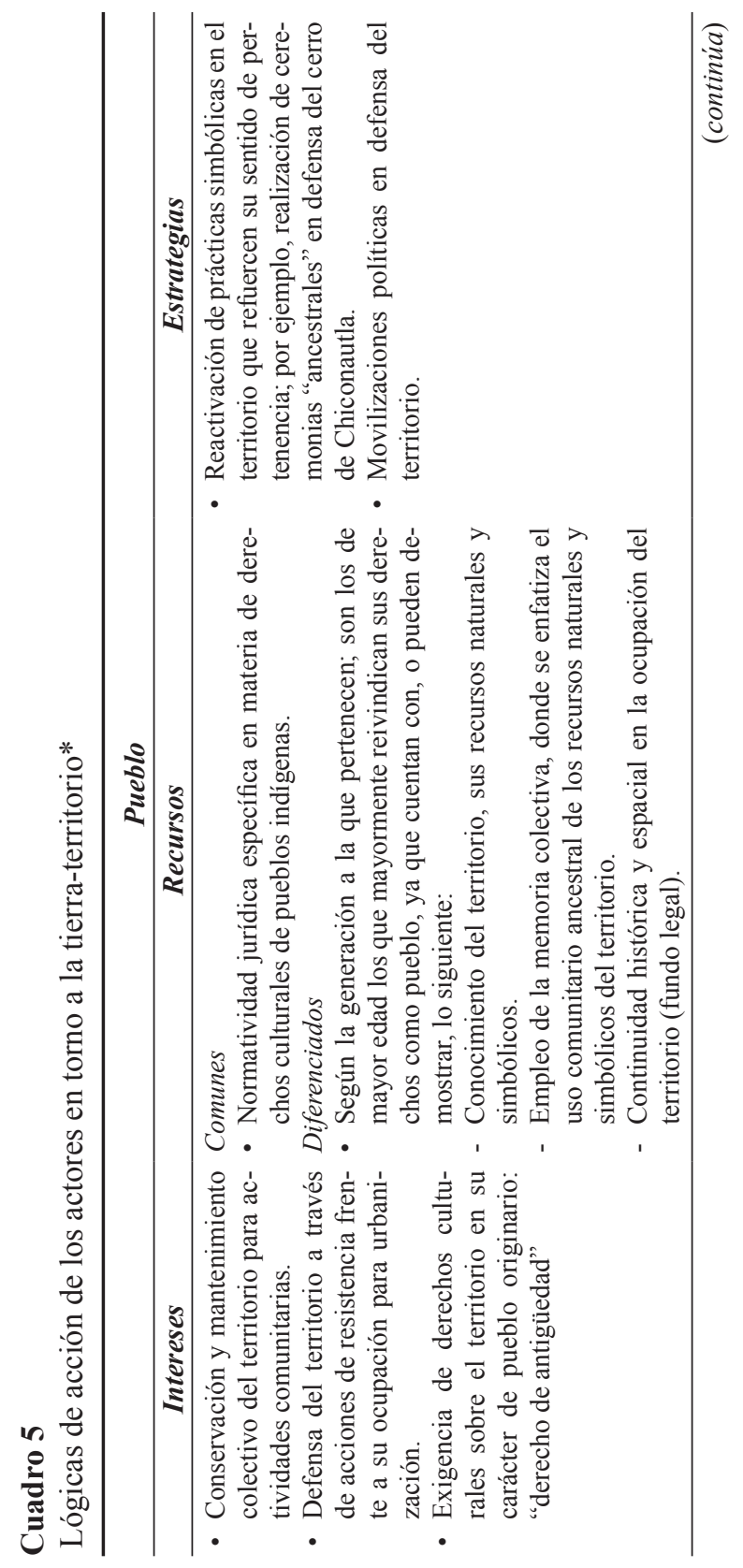




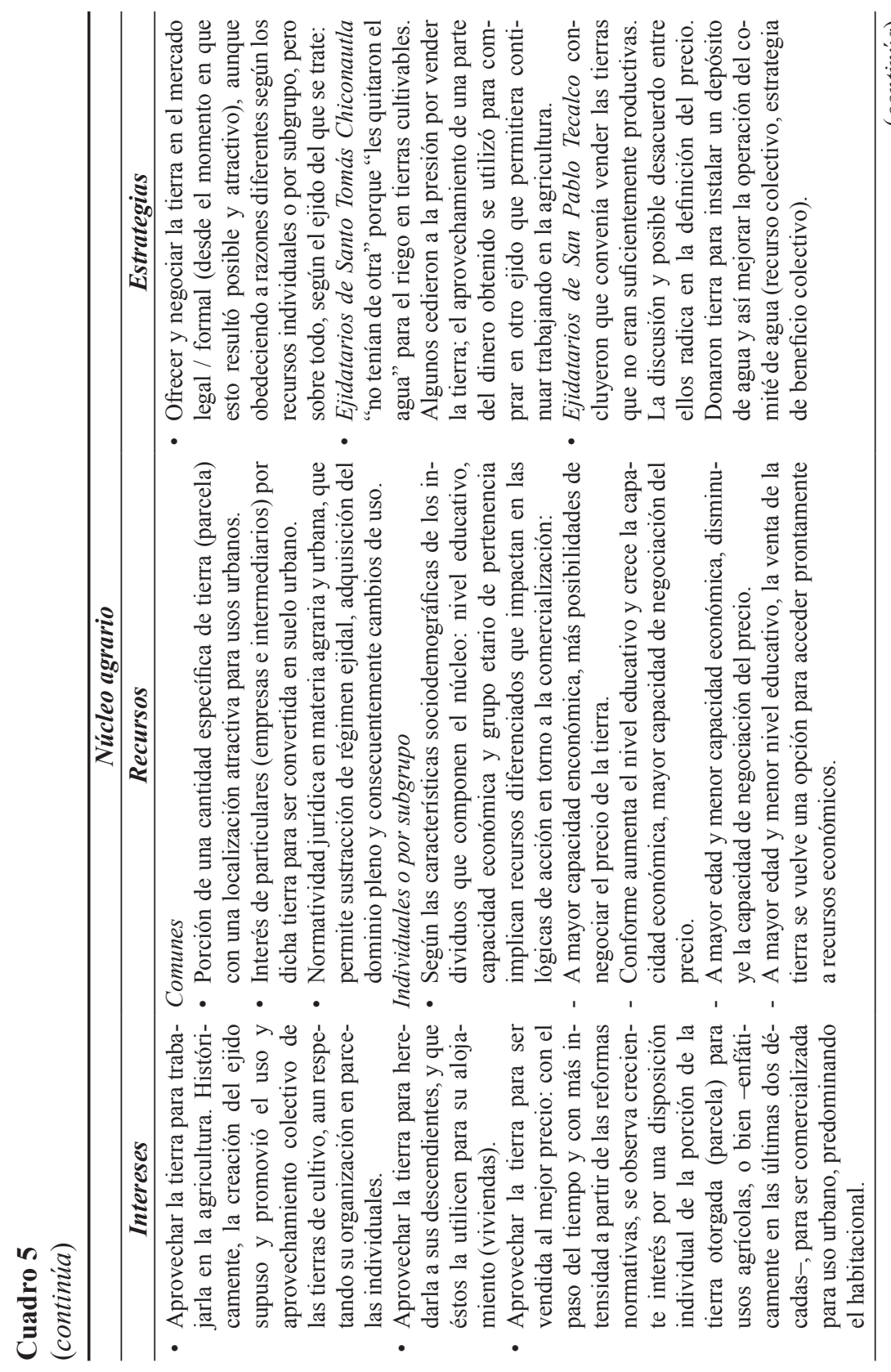




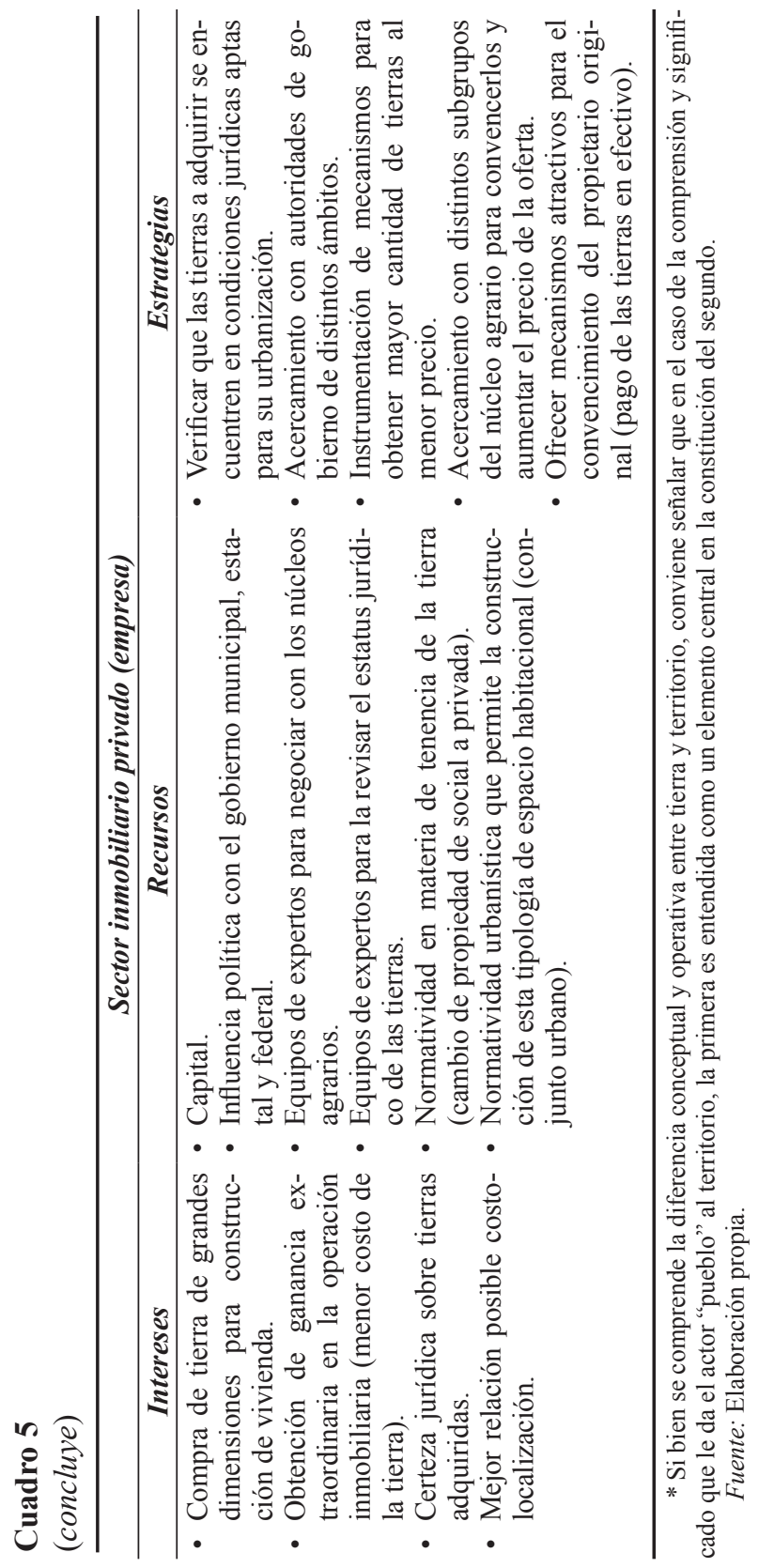


Sin embargo, históricamente existe, por usos y costumbres, la práctica de administración de pozos y dotación del servicio por parte de los pueblos originarios en varios municipios que conforman la metrópoli. Los pueblos reclaman el derecho al control, la administración, la distribución y el cobro de dicho recurso, replicando su facultad de hacerlo según los argumentos señalados líneas antes. Así, los pueblos han venido ejerciendo este control de facto desde décadas atrás, por medio de la creación de comités de agua potable, autónomos o independientes, ${ }^{20}$ que han adquirido en ciertos casos la personalidad jurídica de asociaciones civiles, cuando menos desde la década de 1990.

En los casos de Santo Tomás y San Pablo, son los comités de agua potable quienes controlan, administran, distribuyen y cobran el servicio de agua potable a los habitantes de sus respectivos pueblos, así como de algunas colonias populares aledañas de reciente creación.

Al respecto, existe una coincidencia en los orígenes de dichos comités de agua, los cuales surgen a partir de la instalación de infraestructura hidráulica en las décadas de 1950 y 1960 por parte del gobierno, y con el apoyo de los habitantes de los pueblos, a través del trabajo comunitario, cuando se construyó un pozo y la red hidráulica que surtió a partir de allí el agua a las casas de los pueblos (Mejía, 2017). El comité de agua de Santo Tomás tiene a su cargo tres pozos (Calderón, s/f, p. 5), y el de San Pablo está a cargo de dos.

Los comités están conformados por socios fundadores y habitantes originarios del pueblo, quienes son los que pueden acceder a formar parte de la mesa directiva del comité, así como del padrón de personas que pueden elegir a los miembros de la mesa directiva; los habitantes no originarios están excluidos en tal sentido.

No obstante, en la medida que se han formado algunas colonias alrededor de ambos pueblos, los comités de agua sí han actuado en éstas para la dotación del servicio, cobrándoles las mismas cuotas por conexión a la red, así como por el servicio mensual.

La elección de los integrantes de los comités de agua se hace cada dos años en Santo Tomás y cada cinco años en San Pablo; en el primero es me-

${ }^{20}$ Esta autonomía ha sido negociada con las autoridades de gobierno, en función de que la dotación de dicho servicio es facultad del municipio; sin embargo, los habitantes de los pueblos argumentan que es un derecho que tienen. Cabe destacar que en los últimos años, y a partir de que se ha legislado mayormente al respecto, los pueblos empiezan a utilizar con mayor frecuencia este argumento, incluso, como en el caso del Comité de Agua de San Pablo Tecalco, se dio una modificación en el texto de los contratos con el usuario, en donde se incluye el marco jurídico que los respalda, como el artículo 2 constitucional y el convenio 169 de la OIT (testimonio de un miembro del comité en una asamblea realizada en octubre de 2017). 
diante la elección de planillas ${ }^{21}$ a través de votación en urnas, y en el segundo mediante una propuesta pública en asamblea, en donde se realiza la votación a mano alzada.

La mesa directiva de los comités está compuesta principalmente por un presidente, un secretario y un tesorero, aunque se ayudan de otras personas a las que se les designa como vocales. También se apoyan de empleados, como fontaneros, a quienes los mismos comités solventan con los ingresos que generan.

Si bien los pozos y el caudal de agua que administran no han sido requeridos ni utilizados directamente para la dotación en los nuevos conjuntos urbanos, existe inconformidad por parte de los pueblos y sus comités debido a que, argumentan, ha disminuido la cantidad de agua que extraen de sus pozos por la sobreexplotación de los mantos acuíferos de la región (Mejía, 2017).

El control sobre dicho recurso ha sido motivo de conflicto entre los habitantes originarios de los pueblos y las diferentes instituciones de gobierno, aunque principalmente con el gobierno municipal, lo que incluso ha desencadenado acciones de violencia física (Ibarra, 2017; Mejía 2017; Correa, 2010). No obstante, también se han generado escenarios de negociación entre estos dos actores, lo que ha permitido no sólo el mantenimiento del control del agua por los comités autónomos, sino también el apoyo del gobierno municipal de Tecámac para el financiamiento de la perforación y del equipamiento de un nuevo pozo en el pueblo de San Pablo.

Otro actor que ha estado implicado en la administración, distribución y cobro del agua, así como en el mantenimiento de la red hidráulica, es justamente el gobierno municipal, quien tiene a su cargo un organismo operador o sistema de agua potable, que en Ecatepec se denomina Sistema de Agua Potable, Alcantarillado y Saneamiento (SAPASE), y en el caso de Tecámac, Organismo de Agua Potable, Alcantarillado y Saneamiento (ODAPAS). Éstos son los encargados de dotar del servicio a las distintas colonias en los respectivos municipios, excluyendo aquellas áreas donde se ubican los pueblos, que controlan el recurso con sus comités.

Si bien en diferentes momentos estos organismos han intentado absorber las funciones de los comités autónomos, también es a través de ellos con quienes se establecen relaciones de negociación para la distribución de agua potable a las colonias nuevas que se instalan alrededor de los pueblos.

Un tercer actor en los pueblos que nos ocupan es nuevamente la desarrolladora inmobiliaria Sadasi, la cual ha tenido que construir la infraestruc-

${ }^{21}$ Una planilla está integrada por la fórmula que va a integrar a la mesa directiva: presidente, secretario y tesorero. 
tura hidráulica necesaria para garantizar la satisfacción del recurso en los conjuntos urbanos.

Debido a que la infraestructura hidráulica que construye la desarrolladora es entregada oportunamente a la administración municipal, y ésta es con frecuencia aprovechada para surtir a otros núcleos de población diferentes a los conjuntos urbanos, la empresa busca negociar con las autoridades municipales el compartimiento de algunos gastos iniciales que implica la construcción de dicha infraestructura, que, por lo general, se materializa en descuentos o condonación de pagos por trámites legales que se tienen que hacer en el municipio.

Aun cuando la desarrolladora no estableció un contacto directo con los comités de agua para dotar del recurso hídrico a los conjuntos urbanos, sí ha sido un actor que ha generado movilizaciones de los habitantes de los pueblos por el aprovechamiento del líquido, sobre todo porque estos últimos argumentan que ha disminuido la presión de agua que llega a sus casas, mientras que los segundos afirman que el aprovechamiento del recurso no es un derecho exclusivo de los pueblos.

De la misma manera que en el análisis de actores en torno a la tierra, en el Cuadro 6 se pretende exponer las lógicas de acción de los actores en torno al agua, esquematizadas en la identificación de intereses, recursos y estrategias por cada actor. A diferencia de lo observado con el recurso tierra, aquí pudo advertirse una mayor homogeneidad de comportamientos, derivada, quizás, de una menor diferenciación dentro de cada actor colectivo.

\section{Discusión y conclusiones}

Las condiciones que se han generado en los últimos 25 años en la periferia metropolitana de la Ciudad de México por el acceso y control de los recursos tierra y agua para la urbanización, han propiciado distintas situaciones de tensión y disputa entre viejos y nuevos actores de esos territorios, los cuales presentan lógicas de acción diversas de acuerdo con los intereses que persiguen.

La nueva normatividad en torno a la tierra de propiedad social les ha brindado a los ejidatarios la posibilidad de vender su tierra en condiciones de legalidad, lo cual se ha conjugado con el interés de las empresas desarrolladoras de vivienda por adquirirlas. Sin embargo, el proceso ha sido más complejo de lo que parece, sobre todo por la heterogeneidad de los actores involucrados y la desigual disposición de recursos con los que han contado en el momento de negociar la compraventa de las tierras. 


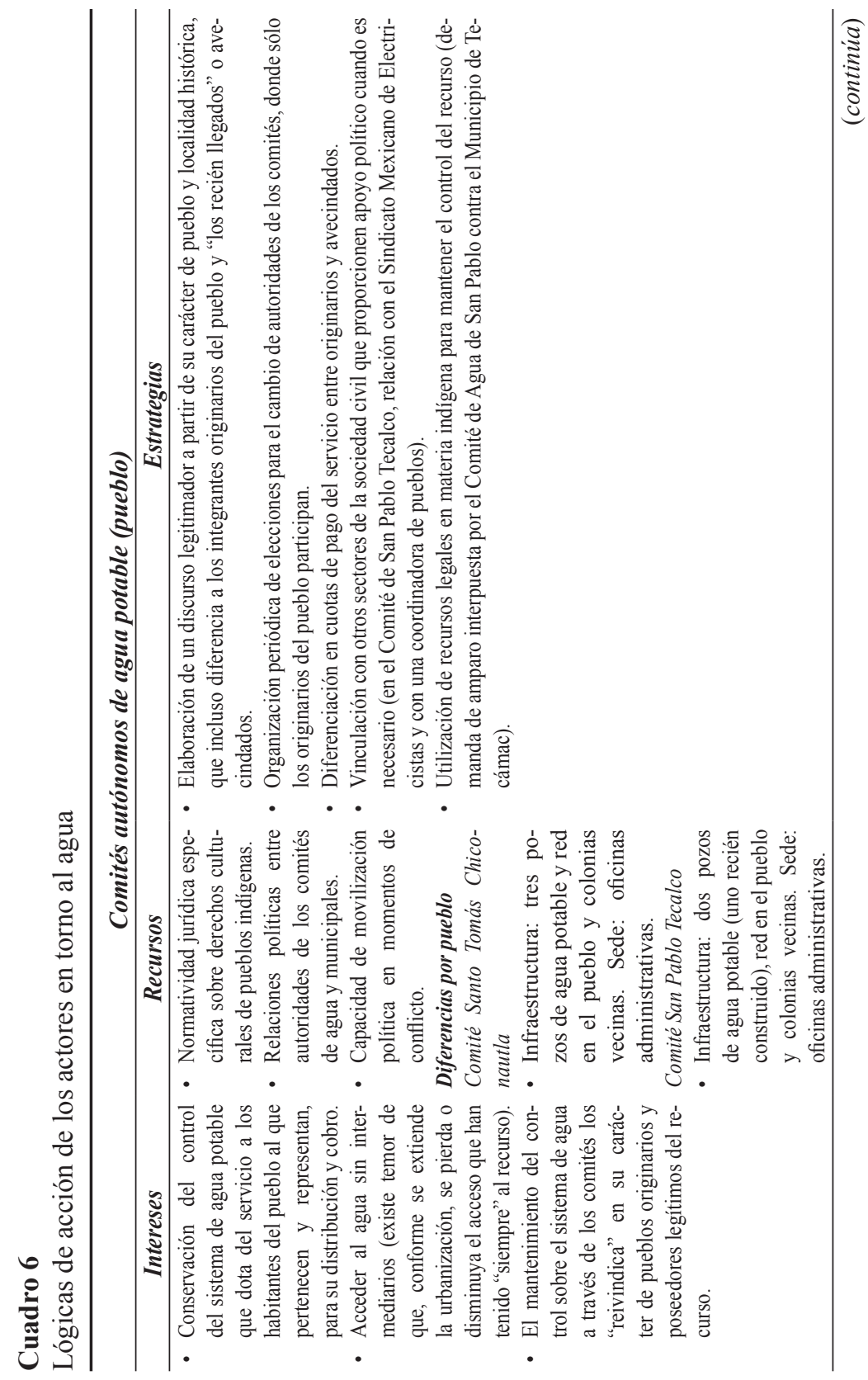




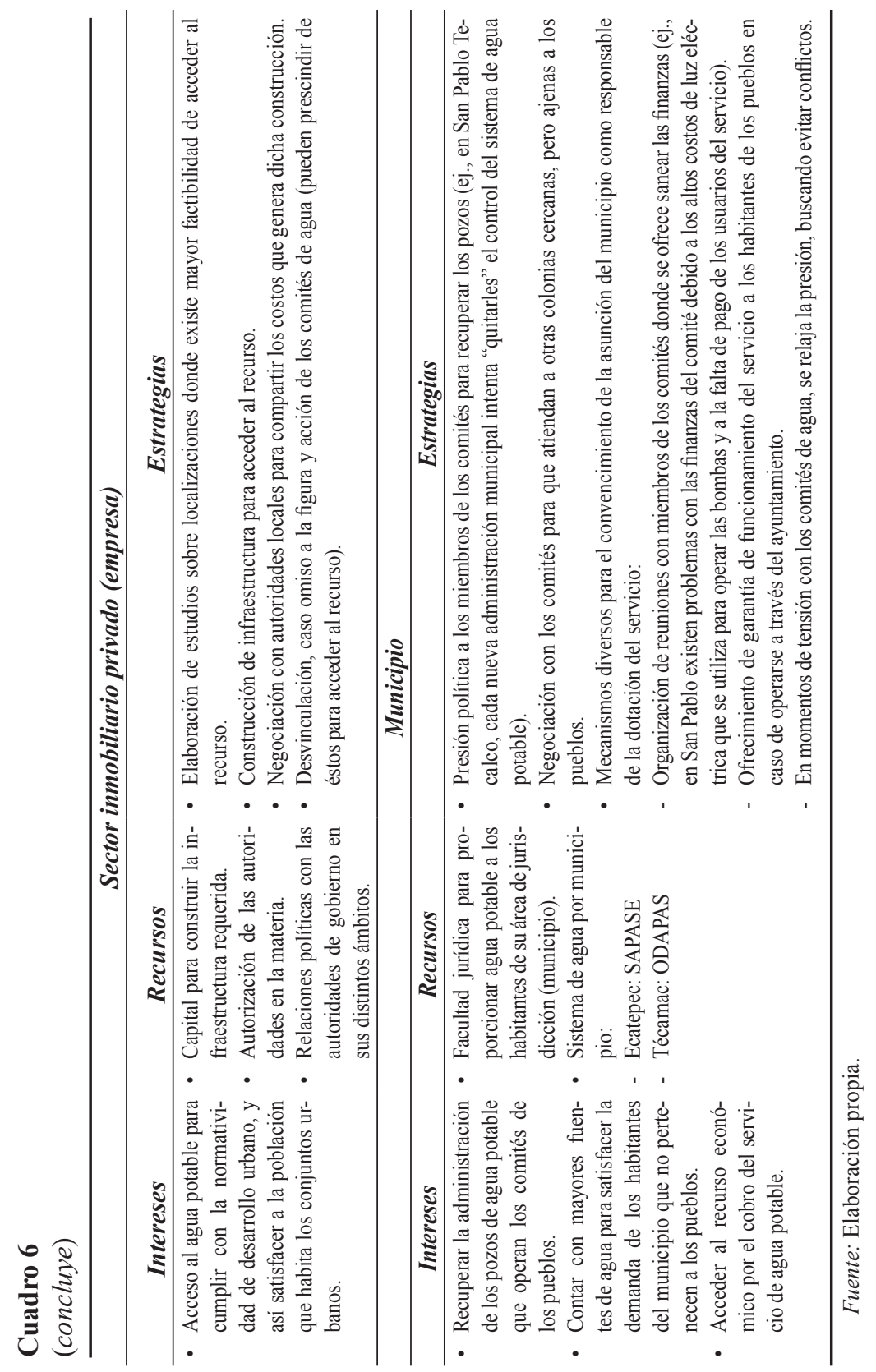


Dicha heterogeneidad se manifiesta también en los propios actores colectivos -como los núcleos agrarios-, en donde los perfiles diferenciados y desiguales entre los ejidatarios condicionaron la posición asumida en el momento de realizar las negociaciones. Por ejemplo, si bien en el núcleo agrario de Santo Tomás Chiconautla la mayoría de los ejidatarios vendió sus tierras para la construcción del conjunto urbano Los Héroes, no todos lo hicieron al mismo precio, incluso hubo algunos que no le vendieron a la desarrolladora, lo que a la postre les benefició porque el valor de su tierra se elevó exponencialmente.

Los recursos del sector inmobiliario, a través de la empresa desarrolladora, se expresaron en diferentes escalas. Por una parte, en el ámbito local, donde su capacidad económica les permitió un margen de maniobra para ofrecer a los ejidatarios cantidades de dinero sumamente atractivas, además de contar con un equipo de especialistas destinados a la negociación y verificación del carácter legal de las tierras. Por otra parte, han tenido la posibilidad de entablar negociaciones políticas con las autoridades de los tres niveles de gobierno para la generación de las condiciones normativas óptimas que les garanticen un mínimo de riesgos para su inversión (Pedrotti, 2016).

En el periodo de tiempo analizado se ha visibilizado otro actor que ha complejizado la urbanización de esta parte de la periferia metropolitana, el pueblo originario. Este actor siempre "ha estado ahí", sin embargo, no había contado con los elementos políticos y jurídicos para negociar sus derechos culturales como actor específico, de los cuales comenzó a gozar a partir de la década de 1990.

Y justo estos nuevos instrumentos legales le han permitido contar con argumentos para demandar una serie de derechos que antes de su promulgación eran ejercidos de facto por los integrantes de los pueblos, como el control del recurso hídrico bajo la conformación de los comités de agua.

En tal sentido, podemos identificar que la visibilización de este actor y su empoderamiento ha propiciado disputas por los recursos tierra y agua con los otros actores involucrados, la desarrolladora inmobiliaria y el gobierno municipal.

Hay que tener presente que esta disputa no ha sido homogénea y con el mismo grado de intensidad, cuando menos en los dos pueblos analizados, ya que mientras en Santo Tomás no existió una disputa muy fuerte con la desarrolladora Sadasi en la mercantilización de las tierras ejidales, en el caso de San Pablo sí, y esto se lo atribuimos a que las condiciones jurídicas y políticas respecto a los derechos de los pueblos se han ido fortaleciendo al paso del tiempo, lo que los ha empoderado (en el caso de Santo Tomás, 
la mayoría de las tierras ejidales se terminaron de urbanizar en la década de 2000; las de San Pablo empezaron dicho proceso desde 2010).

Esto se ha podido identificar, por ejemplo, en las demandas jurídicas que han entablado los miembros del pueblo San Pablo con la desarrolladora Sadasi, en las que la principal demanda son las afectaciones a los recursos naturales que existen en su territorio y a sus prácticas culturales que ha provocado la construcción del conjunto urbano Los Héroes San Pablo.

Otra evidencia se refleja en la conservación, hasta ahora, de la independencia del comité de agua potable en la administración, distribución y cobro del agua a los habitantes de los pueblos -en lugar de hacerlo el gobierno municipal-y en la solidificación del discurso de que el recurso y su administración les pertenecen por el carácter de pueblo originario que tienen y que la Constitución les garantiza como sujetos sociales específicos.

Es importante considerar que también en el interior de los pueblos originarios existe una heterogeneidad en los intereses de sus habitantes; sobre todo porque no a todos les preocupa la disputa de los recursos naturales y culturales, lo cual se refleja, por ejemplo, en la asistencia y el apoyo a los movimientos que han surgido al respecto.

Se han identificado en tal caso disputas por la mercantilización de las tierras de propiedad social entre los ejidatarios y quienes no lo son, donde los primeros argumentan que es su derecho venderlas, mientras que los segundos señalan que ello ha dejado al pueblo en una situación de vulnerabilidad por la sobreexplotación de los recursos naturales que implica la llegada de nuevos habitantes a su territorio.

Para finalizar, lo que este trabajo muestra es la diversidad de actores que han surgido en la expansión metropolitana de la Ciudad de México en los últimos 25 años, los cuales disputan dos de los recursos naturales indispensables para que ello ocurra, la tierra y el agua, utilizando los medios jurídicos, sociales y económicos que tienen a su alcance.

Incluso visibiliza que la disputa por estos recursos va más allá del carácter tangible de los mismos, ya que en las últimas décadas se han incorporado elementos de carácter simbólico y cultural que estos recursos representan para los habitantes de los pueblos, lo cual complejiza la disputa, sobre todo por la legislación que se ha construido en la materia, por la participación política de los habitantes de los pueblos, así como por el carácter heterogéneo de los mismos en la metrópoli.

Un último asunto que se desprende del análisis de los resultados es que, si bien ambos recursos -tierra y agua- son prioritarios para la vida humana (sea cual fuere su aprovechamiento económico y espacial, en ámbitos rurales o urbanos), éstos presentan algunas diferencias en su naturaleza y 
consecuente disponibilidad. Sólo por mencionar un aspecto, la irreproductibilidad, localización fija y aprovechamiento de externalidades que conserva la tierra, no necesariamente se cumple con el agua. Sumado a esto, cada recurso se rige por marcos normativos específicos y distintos entre sí, y su gestión recae también sobre actores distintos.

Lo anterior obliga y estimula a los estudiosos de dichos fenómenos a continuar en la profundización del análisis de los recursos, las condiciones y los actores que surgen en la intervención del territorio para fines urbanos, permitiendo así una mayor comprensión de los mismos.

\section{Bibliografía}

Aguado, E. (1998). Una mirada al reparto agrario en el Estado de México (1915-1992). De la dotación y restitución a la privatización de la propiedad social. Zinacantepec, México: El Colegio Mexiquense, A.C.

Álvarez, L. (2011). Pueblos urbanos: identidad, ciudadanía y territorio en la Ciudad de México. México: Universidad Nacional Autónoma de México, Centro de Investigaciones Interdisciplinarias / Porrúa.

Bassols, M. y Espinosa, M. (2011). Construcción social del espacio urbano: Ecatepec y Nezahualcóyotl. Dos gigantes del oriente. Polis: Investigación y Análisis Sociopolítico y Psicosocial, 7(2), 181-212. Recuperado de http://www.scielo.org.mx/pdf/polis/v7n2/v7n2a7.pdf

Brenner, L. (2010). Gobernanza ambiental, actores sociales y conflictos en las áreas naturales protegidas mexicanas. Revista Mexicana de Sociología, 72(2), 283-310. Recuperado de https://www.jstor.org/ stable/25677044?seq=1\#metadata_info_tab_contents

Calderón, R. (s/f). Territorio, actores y gestión urbana del agua. El caso del municipio Ecatepec de Morelos, Estado de México. Recuperado de https: //fnca.eu/biblioteca-del-agua/directorio/file/1640-1306271428-1829

Conapo. (2012). Delimitación de las Zonas Metropolitanas de México 2010. México: Consejo Nacional de Población. Recuperado de http:// www.conapo.gob.mx/es/CONAPO/Delimitacion_zonas_metropolitanas _2010_Capitulos_I_a_IV

Connolly, P. (2014). La urbanización irregular y el orden urbano en la Zona Metropolitana del Valle de México de 1990 a 2005. En C. Salazar (coord.), Irregular. Suelo y mercado en América Látina (pp. 379-425). Ciudad de México: El Colegio de México, A.C.

Correa, H. (2010). Comunidades históricas en la gran ciudad: emergencia político-cultural en Tecámac, Estado de México. Nueva Antropo- 
logía, 23(73), 59-85. Recuperado de https://www.redalyc.org/articulo. oa? id=15921049004

Cruz, M. S. (2002). Procesos urbanos y ruralidad en la periferia de la Zona Metropolitana de la Ciudad de México. Estudios Demográficos y Urbanos, 17(1), 39-76. Recuperado de https://estudiosdemograficosyurbanos. colmex.mx/index.php/edu/article/view/1129/1122

Cruz, M. S. (2008). Propiedad de la tierra, urbanización ejidal y poblamiento en la Zona Metropolitana del Valle de México 1990-2000. Revista de la Procuraduría Agraria, 38, 45-71. Recuperado de http:// www.pa.gob.mx/publica/rev_38/Mar\%C3\%ADa\%20Soledad $\% 20$ Cruz\%20Rodr\%C3\%ADguez.pdf

Duhau, E. y Giglia, A. (2008). Las reglas del desorden: habitar la metrópoli. Ciudad de México: Universidad Autónoma Metropolitana, unidad Azcapotzalco / Siglo XXI.

Escolero, O., Kralisch, S., Martínez, S. y Perevochtchikova, M. (2016). Diagnóstico y análisis de los factores que influyen en la vulnerabilidad de las fuentes de abastecimiento de agua potable a la Ciudad de México. Boletín de la Sociedad Geológica Mexicana, 68(3), 409-427. Recuperado de http://www.scielo.org.mx/pdf/bsgm/v68n3/1405-3322bsgm-68-03-00409.pdf

Espinosa, M. (2014). Mega proyecto urbano. La ciudad Bicentenario de Tecámac, México. Revista Bitácora Urbano Territorial. 24(2), 31-39. Recuperado de https://www.redalyc.org/articulo.oa?id=74833911006

Fabila, G. y Fabila, M. (1958a). Los ejidos del Estado de México: catálogo. Vol. 2. México: Gobierno del Estado de México, Dirección de Agricultura y Ganadería.

Fabila, G. y Fabila, M. (1958 b). Los ejidos del Estado de México: catálogo. Vol. 3. México: Gobierno del Estado de México, Dirección de Agricultura y Ganadería.

Fernández, P. y De la Vega, S. (2017). ¿Lo rural en lo urbano? Localidades periurbanas en la Zona Metropolitana del Valle de México. Eure. Revista Latinoamericana de Estudios Urbanos Regionales, 43(130), 185-206. Recuperado de https://scielo.conicyt.cl/pdf/eure/v43n130/0250-7161eure-43-130-0185.pdf

Gobierno del Estado de México. (2001). Código Administrativo del Estado de México. Recuperado de http://normateca.edugem.gob.mx/normateca/ wp-content/uploads/2016/07/COD_001.pdf

Gobierno del Estado de México. (2016). Reglamento del libro quinto del Código Administrativo del Estado de México. Recuperado de http:// 
legislacion.edomex.gob.mx/sites/legislacion.edomex.gob.mx/files/ files/pdf/rgl/vig/rglvig107.pdf

Gobierno Municipal de Ecatepec de Morelos. (2016a). Bando Municipal de Ecatepec de Morelos, 2016-2018. Recuperado de https://legislacion. edomex.gob.mx/sites/legislacion.edomex.gob.mx/files/files/pdf/bdo/ bdo034.pdf

Gobierno Municipal de Ecatepec de Morelos. (2016b). Plan de Desarrollo Municipal de Ecatepec de Morelos, 2016-2018. Recuperado de http:// www.versuhen.com/migobiernomunicipal/municipal/guia-1-2-3-delgobierno/pdm--2016-2018.pdf

Gobierno Municipal de Huixquilucan de Degollado. (2016). Bando Municipal de Huixquilucan de Degollado, 2016-2018. Recuperado de https://legislacion.edomex.gob.mx/sites/legislacion.edomex.gob.mx/ files/files/pdf/bdo/bdo2018/bdo039.pdf

Gobierno Municipal de Naucalpan de Juárez. (2016). Bando Municipal de Naucalpan de Juárez, 2016-2018. Recuperado de https://naucalpan. gob.mx/wp-content/uploads/2019/01/17-GACETA-No.-17.pdf

Gobierno Municipal de Tlalnepantla de Baz. (2016). Bando Municipal de Tlalnepantla de Baz, 2016-2018. Recuperado de http://www.tlalnepantla. gob.mx/pages/gaceta/see.php?gaceta=101.pdf

Gobierno Municipal de Tecámac de Felipe Villanueva. (2016). Plan de Desarrollo Municipal de Tecamac de Felipe Villanueva, 2016-2018. Recuperado de https://bit.ly/37OG1eU

Granillo, N. (2006). Tecámac: Monografía Municipal. Programa de Identidad Estatal, Región II. Toluca, Estado de México: Gobierno del Estado de México / Asociación Mexiquense de Cronistas Municipales / Instituto Mexiquense de Cultura.

Ibarra, M. V. (2017). Tensiones y conflictos por agua en el boom inmobiliario de Tecámac, México. Territorios, 37, 81-99. Recuperado de https:// revistas.urosario.edu.co/index.php/territorios/article/view/4818

Instituto Nacional de Estadística y Geografía (INEGI). (1970). IX Censo de Población y Vivienda. Recuperado de https://www.inegi.org. $\mathrm{mx} /$ programas/ccpv/1970/

Instituto Nacional de Estadística y Geografía (INEGI). (1980). X Censo de Población y Vivienda. Recuperado de https://www.inegi.org.mx/ programas/ccpv/1980/

Instituto Nacional de Estadística y Geografía (INEGI). (1990). XI Censo de Población y Vivienda. Recuperado de https://www.inegi.org.mx/ programas/ccpv/1990/ 
Instituto Nacional de Estadística y Geografía (INEGI). (2000). XII Censo de Población y Vivienda. Recuperado de https://www.inegi.org.mx/ programas/ccpv/2000/

Instituto Nacional de Estadística y Geografía (INEGI). (2010). XIII Censo de Población y Vivienda. Recuperado de https://www.inegi.org.mx/ programas/ccpv/2010/

Instituto Nacional de Estadística y Geografía (INEGI). (2015). Encuesta Intercensal de Población y Vivienda, 2015. Recuperado de https:// www.inegi.org.mx/programas/intercensal/2015/

Iracheta, A. (2004). Estado de México: la otra cara de la megaciudad. En P. Ward (coord.), México megaciudad: desarrollo y política, 1970-2002 (pp. 491-607). Zinacantepec, México: El Colegio Mexiquense, A.C.

López, D. (1997). Características de las tierras ejidales de Ecatepec. Así como de los campesinos de los ejidos de Santo Tomás y Santa María Chiconautla en el marco del proceso de urbanización del municipio. (Tesina de licenciatura, área de Sociología Urbana, UAM-Azcapotzalco).

López, P. (2017). Indígenas de la nación: etnografia histórica de la alteridad en México (Milpa Alta, siglos XVII - XXI). Ciudad de México: Fondo de Cultura Económica.

Medina, A. (2007). Los pueblos originarios del sur del Distrito Federal: una primera mirada etnográfica. En A. Medina (coord.), La memoria negada de la Ciudad de México: sus pueblos originarios (pp. 29-124). Ciudad de México: Universidad Nacional Autónoma de México / Universidad Autónoma de la Ciudad de México.

Mejía, I. (2015). Territorio, poblamiento y sentidos de pertenencia en Ecatepec de Morelos 1930-2014. (Tesis de maestría, El Colegio Mexiquense, A.C).

Mejía, I. (2017). De pueblos ribereños a pueblos urbanos: la lucha por el control del agua. En A. Iracheta Cenecorta, C. I. Pedrotti y P. Rodríguez Alomá (coords.), Suelo urbano y frentes de agua. Debates y propuestas en Iberoamérica (pp. 153-170). Zinacantepec, México: El Colegio Mexiquense, A.C.

Mejía, I. (2018). Pueblos originarios en la periferia metropolitana, sus procesos de continuidad y cambio. Santo Tomás Chiconautla y San Pablo Tecalco. (Tesis de doctorado en proceso, El Colegio Mexiquense, A.C.).

Pedrotti, C. (2016). Calidad residencial y condiciones de producción en la vivienda social promovida por el sector privado: Zona Metropolitana de Toluca, 2001-2011. México: Universidad Nacional Autónoma de México / Infonavit. 
Pírez, P. (1995). Actores sociales y gestión de la ciudad. Ciudades. Gestión urbana y poder local, 28, 1-12. Recuperado de http://gestproyecto. galeon.com/actsocia.pdf

Rodríguez, A. R. (2015). Urbanización de la región Huehuetoca-Zumpango-Tecámac, del Estado de México: entorno al desarrollo de vivienda (Tesis de maestría inédita, Instituto Mora).

Salazar, C. (2000). La relación población-recursos en la periferia urbana. Una experiencia teórico-metodológica, Estudios Demográficos y Urbanos, 15(3), 641-664. Recuperado de https://estudiosdemograficosyurbanos. colmex.mx/index.php/edu/article/view/1089/1082

Salazar, C. (2010). Oferta potencial de suelo social en la Zona Metropolitana del Valle de México: una lectura a partir de la certificación ejidal. En A. Iracheta, y E. Soto (coords.), Impacto de la vivienda en el desarrollo urbano (pp. 307-332). Zinacantepec, México: El Colegio Mexiquense, A.C.

Salazar, C. (2014). Los ejidatarios en el control de la regularización. En C. E. Salazar (coord.), Irregular. Suelo y mercado en América Látina (pp. 265-305). Ciudad de México: El Colegio de México, A.C.

Salgado, A. (2017). Autoridades tradicionales en Xochimilco se nombrarán por usos y costumbres. La Jornada. Recuperado de http://semanal. jornada.com.mx/ultimas/2017/06/11/autoridades-tradicionales-enxochimilco-se-nombraran-por-usos-y-costumbres

Salinas, C. (2016). Entre la modernidad y las viejas formas corporativas: el distrito de Tlalnepantla durante el porfiriato. En M. P. Iracheta (coord.), Tlalnepantla (pp. 67-133). Zinacantepec, Estado de México: El Colegio Mexiquense, A.C.

Segura, R. (2011). La trama relacional de la periferia de la Ciudad de la Plata. La figuración "establecidos-outsiders" revisitada. Publicar-En Antropología y Ciencias Sociales, 9(10), 85-106. Recuperado de http:// ppct.caicyt.gov.ar/index.php/publicar/article/view/1200/1056

\section{Acerca de los autores}

Ismael Mejía Hernández es doctorante en Ciencias Sociales por El Colegio Mexiquense A.C., maestro en Ciencias Sociales con especialidad en Desarrollo Municipal por El Colegio Mexiquense A.C., y antropólogo social por la Escuela Nacional de Antropología e Historia. Cursó el diplomado Derechos de los Pueblos Indígenas: Doctrina, Legislación, Tratados y Jurisprudencia, del Instituto Nacional de Antropología e Historia. Realizó 
una estancia internacional en la Universidad Mayor de San Simón, en Cochabamba, Bolivia, durante 2017.

Desde 2016 es co-coordinador del Seminario Permanente Ecatepec a lo Largo de la Historia, del Centro Comunitario Ecatepec Casa de Morelos, la Dirección de Etnohistoria del Instituto Nacional de Antropología e Historia y Yaollin Ehecatl, A.C. Es profesor de asignatura de la Universidad Autónoma de la Ciudad de México.

Sus líneas de investigación están centradas en los procesos de urbanización de los municipios Ecatepec de Morelos y Tecámac de Felipe Villanueva, Estado de México, así como en los pueblos originarios que se encuentran en la periferia metropolitana de la Ciudad de México. ORCID: https://orcid.org/0000-0003-3857-6710

Entre sus publicaciones se encuentra:

Mejía, I. (2017). De pueblos ribereños a pueblos urbanos: la lucha por el control del agua. En A. X. Iracheta, C. I. Pedrotti y P. Rodríguez (coords.). Suelo urbano y frentes de agua: debates y propuestas en Iberoamérica (pp. 153-170). Zinacantepec, México: El Colegio Mexiquense.

Carolina Inés Pedrotti es doctora en Urbanismo por la Universidad Nacional Autónoma de México, maestra en Estudios Urbanos y Regionales por la Universidad Autónoma del Estado de México, y arquitecta por la Universidad Nacional de Córdoba, Argentina. Es miembro del Sistema Nacional de Investigadores, nivel I. Ha realizado otros estudios de posgrado en desarrollo, mejoramiento y gestión habitacional en Bolivia (Instituto de Investigaciones de Arquitectura de la Universidad Mayor de San Simón) y Costa Rica (Fundación Promotora de Vivienda), organizados y promovidos por el departamento Housing, Development and Management, de la Universidad de Lund, Suecia.

Desde 2008 es profesora-investigadora de El Colegio Mexiquense, A.C., donde de 2016 a 2019 coordinó la maestría en Ciencias Sociales, con especialidad en Desarrollo Municipal. Es docente en la Facultad de Arquitectura y Diseño de la Universidad Autónoma del Estado de México, en la licenciatura en Administración y Promoción de la Obra Urbana.

Sus líneas de investigación abordan el suelo urbano y la vivienda, en los temas que comprenden las formas de producción habitacional, las políticas habitacionales -su formulación e implementación en los distintos ámbitos de gobierno-, y el funcionamiento de los mercados inmobiliarios en las ciudades de México.

En 2016 recibió el primer lugar -en la modalidad tesis doctoral- del Premio Internacional de Tesis de Investigación 2015 Vivienda y Habitabilidad, una Perspectiva Regional, que otorgan la UNAM (a través del Programa 
Universitario de Estudios sobre la Ciudad) y el Infonavit, con la tesis Calidad residencial y condiciones de producción en la vivienda social promovida por el sector privado. Zona Metropolitana de Toluca, 2001-2011, que fue publicada en ese año. ORCID: https://orcid.org/0000-0003-0379-8831

Otras publicaciones recientes son:

Pedrotti, C. I. (2017). La gestión de la política habitacional en el Estado de México para la producción de conjuntos urbanos. En A. Ziccardi y D. Cravacuore (coords.), Los gobiernos locales y las politicas de vivienda en México y América Latina. Ciudad de México: Universidad Nacional Autónoma de México, Coordinación de Humanidades, Programa Universitario de Estudios sobre la Ciudad.

Gargantini, D. M. y Pedrotti, C. I. (2018). Capacidades institucionales del gobierno municipal en el diseño y gestión de políticas habitacionales. Economía, Sociedad y Territorio, 18(57), 319-357. DOI: http://dx.doi. org/10.22136/est2018113

Recepción: 9 de agosto de 2018.

Aceptación: 17 de diciembre de 2018. 